\title{
Contributions of Rod and Cone Pathways to Retinal Direction Selectivity Through Development
}

\author{
ㄱuliana M. Rosa, ${ }^{1}$ Ryan D. Morrie, ${ }^{1}{ }^{\oplus}$ Hans C. Baertsch, ${ }^{1}$ and ${ }^{\circledR}$ Marla B. Feller ${ }^{1,2}$ \\ ${ }^{1}$ Department of Molecular and Cell Biology and ${ }^{2}$ Helen Wills Neurosciences Institute, University of California, Berkeley, California 94720
}

Direction selectivity is a robust computation across a broad stimulus space that is mediated by activity of both rod and cone photoreceptors through the $\mathrm{ON}$ and $\mathrm{OFF}$ pathways. However, rods, S-cones, and M-cones activate the $\mathrm{ON}$ and $\mathrm{OFF}$ circuits via distinct pathways and the relative contribution of each to direction selectivity is unknown. Using a variety of stimulation paradigms, pharmacological agents, and knockout mice that lack rod transduction, we found that inputs from the $\mathrm{ON}$ pathway were critical for strong direction-selective (DS) tuning in the OFF pathway. For UV light stimulation, the ON pathway inputs to the OFF pathway originated with rod signaling, whereas for visible stimulation, the $\mathrm{ON}$ pathway inputs to the OFF pathway originated with both rod and M-cone signaling. Whole-cell voltageclamp recordings revealed that blocking the $\mathrm{ON}$ pathway reduced directional tuning in the OFF pathway via a reduction in null-side inhibition, which is provided by OFF starburst amacrine cells (SACs). Consistent with this, our recordings from OFF SACs confirmed that signals originating in the $\mathrm{ON}$ pathway contribute to their excitation. Finally, we observed that, for UV stimulation, ON contributions to OFF DS tuning matured earlier than direct signaling via the OFF pathway. These data indicate that the retina uses multiple strategies for computing DS responses across different colors and stages of development.

Key words: development; direction selectivity; direction selective ganglion cells; Gnat1; retina; rod/cone pathway

Significance Statement

The retina uses parallel pathways to encode different features of the visual scene. In some cases, these distinct pathways converge on circuits that mediate a distinct computation. For example, rod and cone pathways enable direction-selective (DS) ganglion cells to encode motion over a wide range of light intensities. Here, we show that although direction selectivity is robust across light intensities, motion discrimination for OFF signals is dependent upon $\mathrm{ON}$ signaling. At eye opening, $\mathrm{ON}$ directional tuning is mature, whereas OFF DS tuning is significantly reduced due to a delayed maturation of S-cone to OFF cone bipolar signaling. These results provide evidence that the retina uses multiple strategies for computing DS responses across different stimulus conditions.

\section{Introduction}

One of the remarkable properties of the retina is its ability to encode visual features for both $\mathrm{ON}$ and OFF polarity in light intensities that vary across several orders of magnitude and spectral content. For

Received Oct. 19, 2015; revised July 11, 2016; accepted July 28, 2016

Author contributions: J.M.R. and M.B.F. designed research; J.M.R., R.D.M., H.C.B., and M.B.F. performed research; J.M.R., R.D.M., H.C.B., and M.B.F. analyzed data; J.M.R., R.D.M., H.C.B., and M.B.F. wrote the paper.

This work was supported by National Institutes of Health (Grants R01EY019498, R01EY013528, and P30EY003176 to J.M.R. and M.B.F.) and the National Science Foundation (Graduate Research Fellowship DGE 1106400 to R.D.M.). Some images were acquired in the Molecular Imaging (enter at the University of Berkeley. We thank Dr. Jeannie Chen (University of Southern California) for kindly providing the initial breeding of Gnat $1^{-1}$ mice; Dr. Christian Gainer for imaging support and visual stimulation design; Hillel Adesnik for the use of the macroscope; Margaret Veruki and Espin Hartveit for assistance in retinal slices; and all members of the Feller laboratory for helpful comments on this manuscript.

The authors declare no competing financial interests.

Correspondence should be addressed to: Marla B. Feller, Ph.D., Department of Molecular and Cell Biology \& Helen Wills Neuroscience Institute, University of California, Berkeley, 142 Life Sciences Addition 3200, Berkeley, CA 94720 3200.E-mail:mfeller@berkeley.edu.

DOI:10.1523/JNEUROSCI.3824-15.2016

Copyright $\odot 2016$ the authors $\quad 0270-6474 / 16 / 369683-13 \$ 15.00 / 0$ example, direction-selective ganglion cells (DSGCs), which fire strongly when an object moves in the preferred direction (PD) and fire minimally when the object moves in the opposite (null) direction (ND) (Fig. 1B), show similar tuning across different light intensities (Hoggarth et al., 2015). Responses across light conditions are mediated by different classes of photoreceptors: rod photoreceptors are active at low light levels, whereas S-cone and M-cone photoreceptors become active at bright light levels. In the mouse retina, rod-mediated signaling also contributes to visual processing in intermediate and bright light conditions (Ke et al., 2014; Szikra et al., 2014; Vlasits et al., 2014; Grimes et al., 2015; Tikidji-Hamburyan et al., 2015; Joesch and Meister, 2016), indicating that a complex set of interactions between rod and cone pathways influence the encoding features of the retina.

Cones and rods feed into circuits that are initially distinct in the outer retina, but then converge onto the same cell types in the inner retina (Fig. 1A). Cones synapse onto two major subtypes of cone bipolar cells (cBCs): ON cBCs that depolarize in response to increases in light and OFF cBCs that depolarize in response to de- 
A

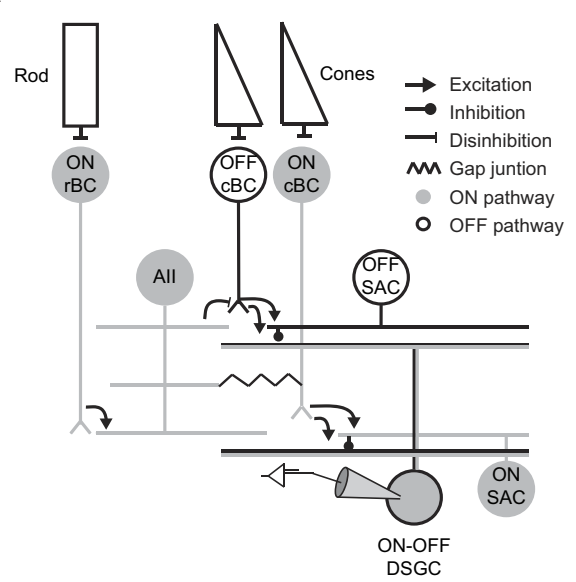

B

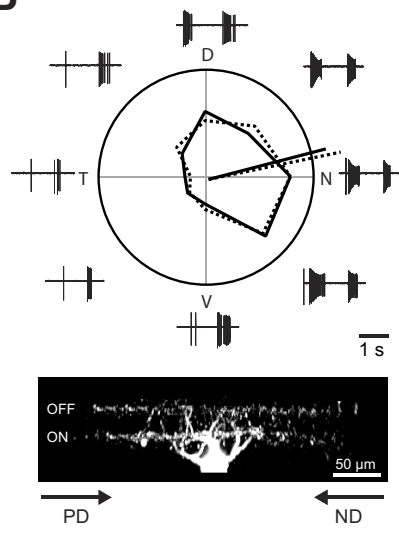

C
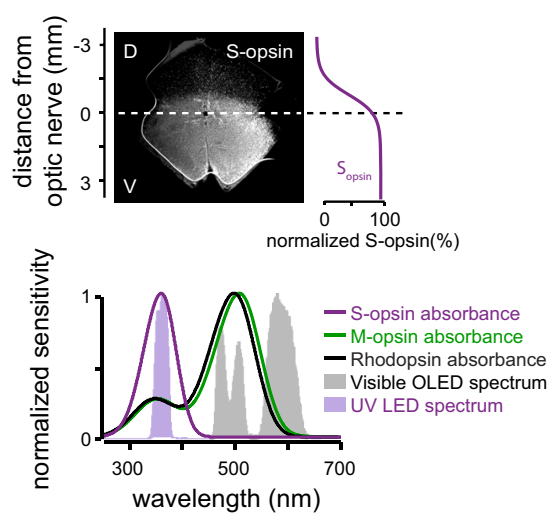

D

UV light, ventral retina

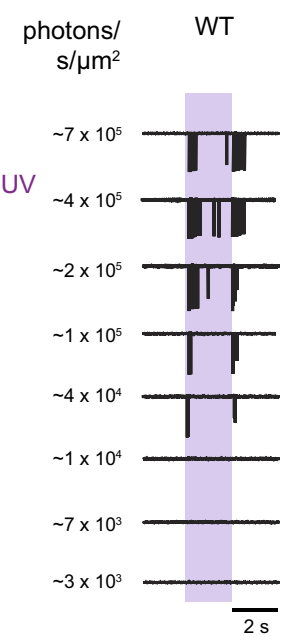

E

photons/

bright $\sim 7 \times 10^{5}$

$\sim 5 \times 10^{4}$
$\operatorname{dim} \sim 3 \times 10^{4}$

$\sim 1 \times 10^{4}$

$\sim 5 \times 10^{3}$

$\sim 3 \times 10^{3}$

$\sim 2 \times 10^{3}$

$\sim 1 \times 10^{3}$
Visible light, ventral retina

WT

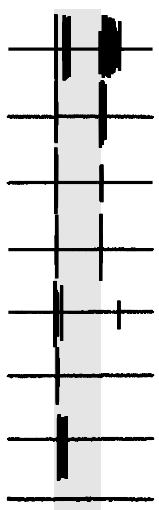

Gnat1-

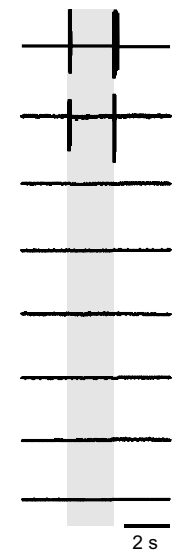

F

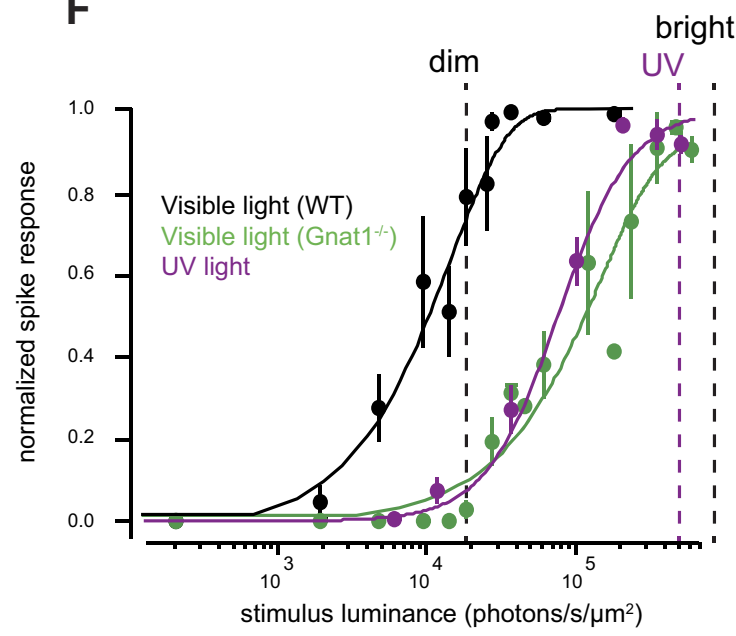

Figure 1. Preferential activation of rod, M-cone, and S-cone pathways. A, Schematic of retinal circuitry shows signaling through rod and cone pathways onto an ON-OFF DSGC. In the cone pathway, cone bipolar cells depolarize to increments (ON CBC, gray) or decrements (OFF CBC, white) of background illumination. These CBCs activate the ON-OFF DSGC and SACS. SACs then provide inhibitory input onto DSGCS. In the rod pathway, increments in light cause ON rBCs to excite All amacrine cells that in turn "piggyback" onto the ON cone pathway through sign-preserving electrical synapses and onto the OFF cone pathway via sign-inverting glycinergic synapses, which produce excitation to decrements in light through disinhibition. ON CBCs can also influence OFF CBCs through their electrical synapse with the All amacrine. This $\mathrm{ON}$ contribution to the OFF pathway is referred to as crossover signaling. $\boldsymbol{B}$, Top, Example of two-photon targeted cell-attached recordings from the GFP + cell shown on bottom in which GFP is expressed in a nasally tuned subtype of ON-OFF DSGC. Spike responses to moving bars, with ON responses preceding OFF responses. Polar plot indicates the mean spike counts of responses to motion in eight directions across three repetitions. Tuning curves (black and dotted outline) were obtained using the mean spike counts in response to each direction. The straight lines inside the tuning curves denote their respective vector sums. N, T, D, and V indicate the retinal cardinal directions, i.e., nasal, temporal, dorsal and ventral, respectively. Bottom, Side view of a two-photon reconstruction of the targeted DSGC filled with Alexa Fluor 594 showing dendritic stratification in the ON and OFF sublaminae of the inner plexiform layer. Black arrows indicate the PD and ND motion. C, Top, Staining for S-opsin in whole-mount mouse retina showing the dorsal (D) to ventral (V) gradient of expression. Distribution graph on right indicates normalized fluorescence values for this staining (see also Fig. 7). Dashed line represents location of optic nerve head. Bottom, Spectral sensitivity of rhodopsin (rods, black line), M-opsin (M-cones, green line), and S-opsin (S-cones, magenta line) with the spectra of light stimuli denoted by colored bars: magenta (UV LED for UV light) and gray (OLED for visible light). D, E, Cell-attached recordings from $0 \mathrm{~N}-0$ FF DSGCs in ventral retina in response to flashing spots (200 $\mu \mathrm{m}$ diameter, $2 \mathrm{~s}$ ) of increasing intensities of UV light in WT mice (D); or visible light in WT and Gnat ${ }^{-1-}$ mice (E). Purple and gray bars indicate the timing of light stimulation. $\boldsymbol{F}$, Averaged normalized spike response as a function of stimulation luminance across the recorded population of ON-0FF DSGCS (black, WT, visible light $=18$ cells; green, Gnat $1^{-I-}$, visible light $=14$ cells; magenta, WT, UV light $=8$ cells). Normalized data represent the total number of spikes in response to a stimulus divided by the total number of spikes in response to the maximum intensity for that light stimulation. Solid lines indicate fits of the Hill function with ${ }_{\text {half }}=1.16 \times 10^{4}$ photons $/ \mathrm{s} / \mu \mathrm{m}^{2}$ in WT with visible light; $1.38 \times 10^{5}$ photons $/ \mathrm{s} / \mu \mathrm{m}^{2}$ in $\mathrm{Gnat} 1^{-1-}$ with visible light and $7.59 \times 10^{4} \mathrm{photons} / \mathrm{s} / \mu \mathrm{m}^{2}$ in WT with UV light. Error bars indicate \pm SD.

creases in light. Both $\mathrm{ON}$ and $\mathrm{OFF} \mathrm{cBCs}$ then make excitatory synapses onto ON and OFF retinal ganglion cells (RGCs). Rods synapse onto a single type of rod bipolar cell (rBC) that depolarizes in response to increases in light. The $\mathrm{rBC}$ then makes excitatory synapses onto AII amacrine cells, which send rod signals to both ON cBCs via gap junctions and $\mathrm{OFF}$ cBCs via glycinergic inhibitory synapses (Oesch et al., 2011; Demb and Singer, 2012). The AII amacrine-ON cBC gap junction is also a robust source of crossover signaling from ON cBCs to OFF cBCs (Manookin et al., 2008; Mol- nar et al., 2009; Werblin, 2011). Therefore, the ON and OFF cBCs integrate signals generated in both the rod and cone pathways.

Here, we studied how these interactions between $\mathrm{ON}$ and OFF pathways underlie the consistency of direction-selective (DS) tuning across light intensities. The synaptic mechanism of DS circuits is established by a precise wiring of presynaptic starburst amacrine cells (SACs) onto DSGCs (Briggman et al., 2011), which creates asymmetric inhibition that shunts light-evoked excitation when an object moves in the ND. We used two-photon 
Table 1. Visual stimuli

\begin{tabular}{|c|c|c|c|c|c|c|c|}
\hline \multirow[b]{2}{*}{ Description } & \multirow{2}{*}{$\begin{array}{l}\text { Stimulus } \\
\text { (photons } / \mathrm{s} / \mu \mathrm{m}^{2} \text { ) }\end{array}$} & \multirow{2}{*}{$\begin{array}{l}\text { Background } \\
\text { (photons } / \mathrm{s} / \mu \mathrm{m}^{2} \text { ) }\end{array}$} & \multirow{2}{*}{$\begin{array}{l}\text { Michaelson } \\
\text { or Weber contrast }\end{array}$} & \multirow[b]{2}{*}{ Opsin } & \multicolumn{3}{|l|}{ Stimulus $^{a}$} \\
\hline & & & & & $R^{*} / \mathrm{rod} / \mathrm{s}$ & $\mathrm{R}^{*} / \mathrm{M}$-cones $/ \mathrm{s}$ & $\mathrm{R}^{*} / \mathrm{S}$-cone $/ \mathrm{s}$ \\
\hline Dim visible stimulation (OLED) & $2.7 \times 10^{4}$ & $1.8 \times 10^{2^{b}}$ & Weber $=269 \%$ & Rod & $8.1 \times 10^{4}$ & $5.6 \times 10^{3}$ & - \\
\hline \multirow[t]{3}{*}{ Bright visible stimulation (OLED) } & $9.7 \times 10^{5}$ & $6.3 \times 10^{4}$ & Weber $=96 \%$ & \multirow{3}{*}{ M-opsin and rod } & \multirow[t]{3}{*}{$3.1 \times 10^{5}$} & \multirow[t]{3}{*}{$2.0 \times 10^{4}$} & \multirow[t]{3}{*}{-} \\
\hline & $6.3 \times 10^{4}$ & $1.2 \times 10^{5}$ & Weber $=-11 \%$ & & & & \\
\hline & $6.3 \times 10^{4}$ & $7.2 \times 10^{5}$ & Weber $=-71 \%$ & & & & \\
\hline Bright UV stimulation (375 nm LED) & $5.1 \times 10^{5}$ & $\sim 0$ & Michaelson contrast $=100 \%$ & S-opsin, M-opsin, and rod & $7.0 \times 10^{4}$ & $5.5 \times 10^{3}$ & $4.5 \times 10^{5}$ \\
\hline Green stimulation (535 nm) & $6.4 \times 10^{5}$ & $\sim 0$ & Michaelson contrast $=100 \%$ & M-opsin and rod & $3.5 \times 10^{5}$ & $2.6 \times 10^{4}$ & - \\
\hline
\end{tabular}

Light stimuli were generated with either a broadband OLED or a $375 \mathrm{~nm}$ or $535 \mathrm{~nm}$ LED masked by a digital mirror device (Figure 1C). Photon flux was estimated as the average intensity measured with a power meter placed at the focal plane. Intensity values were converted to photoisomerizations per rod and assumed a rod cross-section of $0.85 \mu \mathrm{m}^{2}$ and a cone cross-section of $1 \mu \mathrm{m}^{2}$.

${ }^{a}$ Assuming $5 \%$ M-opsin in ventral retina where recordings were done as per Wang et al. (2011).

${ }^{b}$ Below sensitivity of power meter. For OLED, we estimated by assuming $27 \%$ transmission through neutral density filter.

targeted cell-attached and whole-cell recordings from DSGCs and SACs to determine the relative contribution of the rod, $\mathrm{M}$-cone and S-cone pathways to the excitation and inhibition underlying both ON and OFF direction selectivity. In addition, we investigate how these circuit mechanisms emerge during development.

\section{Materials and Methods}

Animals. All mice used in this study were younger than postnatal day 55 (P55). To target DSGCs, we used TRHR-GFP mice, which express GFP in nasal preferring DSGCs (Rivlin-Etzion et al., 2011). Mice of either sex were obtained from Mutant Mouse Regional Resource Centers (http://www. mmrrc.org/strains/30036/030036.html) (Gong et al., 2003) and crossed with C57BL/ 6 mice in our laboratory. Gnat ${ }^{-1-}$ mice, which lack the $\alpha$-subunit of rhodopsin transducin and thus lack rod signaling (Calvert et al., 2000), were crossed with TRHR-GFP mice in our laboratory. To target SACs, we used metabotropic glutamate receptor 2 (mGluR2)-GFP mice, which contain a transgene insertion of interleukin-2 receptor fused GFP under control of the mGluR2 promoter (Watanabe et al., 1998) and express GFP in all SACs (Yoshida et al., 2001). All animal procedures were approved by the University of California-Berkeley Animal Care and Use Committees and conformed to the National Institutes of Health's Guide for the Care and Use of Laboratory Animals, Public Health Service Policy, and the Society for Neuroscience Policy on the Use of Animals in Neuroscience Research.

Immunohistochemistry to identify cones containing S-opsins or $M$-opsins. Whole-mount retinas were placed photoreceptor side up on a membrane, fixed in $4 \%$ paraformaldehyde for $30 \mathrm{~min}$, rinsed in blocking solution (2\% bovine serum albumin, $2 \%$ donkey serum, $0.3 \%$ Triton $\mathrm{X}-100$ in PBS, 3 times, $20 \mathrm{~min}$ at room temperature), and left in blocking solution overnight at $4^{\circ} \mathrm{C}$. They were then incubated in the following primary antibodies diluted in blocking solution at $4^{\circ} \mathrm{C}$ for $3 \mathrm{~d}$ : goat anti-S-opsin (1:1000, Santa Cruz Biotechnology, catalog sc-14363, lot G1014) or rabbit anti-M-opsin (1:1000, Millipore, catalog AB5405 lot 2470968), rinsed in blocking solution (3 times, $20 \mathrm{~min}$ ), and incubated in the following secondary antibodies at room temperature for $2 \mathrm{~h}$ : donkey anti-goat (1:1000, Alexa Fluor 488, Invitrogen, catalog A-11055, lot 1605893) for S-opsin or donkey anti-rabbit (1:1000, Alexa Fluor 488, Invitrogen, catalog A21206, lot: 1110071) for M-opsin. After retinas were rinsed again in blocking solution (3 times, $20 \mathrm{~min}$ ), they were mounted on slides in antifade medium containing 4',6-diamidino-2-phenylindole.

Full retina fluorescence images were acquired on an Olympus MVX10 macroscope equipped with a $488 \mathrm{~nm}$ laser line and an Olympus MV PLAPO 2XC objective. High-magnification imagines were acquired on a Zeiss LSM 710 laser scanning confocal microscope equipped with a 488 nm laser line and a Plan-Apochromat $63 \times / 1.4$ oil diffusion interference contrast objective.

To determine the number of S-opsin- and M-opsin-expressing cones in whole-mount retinas, we first obtained confocal images of 3 different fields of view $\left(0.12 \mathrm{~mm}^{2}\right.$ each $)$ from dorsal portions and 3 fields of view from ventral portions of the retina, all located $1.3 \mathrm{~mm}$ away from the optic nerve. For each field of view, the number of S-opsin-expressing cones was determined using a custom-based algorithm (IgorPro; Wavemetrics). The algorithm created a binary image, and then detected objects within this binary image. To minimize false positives, objects were filtered using a range of sizes. To validate this approach, the number of objects identified using the algorithm was compared with the number acquired by manually counting objects in randomly selected images. The number of objects in the three fields of view were then averaged and reported as number of S-opsin- or M-opsin-expressing cones per square millimeter (see Fig. 7C).

Two-photon targeted recordings from GFP D DGCs and SACs. Filterpaper-mounted retinas were placed under the microscope in oxygenated Ames' medium at $32-34^{\circ} \mathrm{C}$. Identification and recordings from $\mathrm{GFP}^{+}$ cells were performed as described previously (Wei et al., 2010). In brief, $\mathrm{GFP}^{+}$cells were identified using a custom-modified two-photon microscope (Fluoview 300; Olympus America) tuned to $920 \mathrm{~nm}$ to minimize bleaching of photoreceptors. Average laser power at the sample was $13 \pm$ $5 \mathrm{nW}$. The inner limiting membrane above the targeted cell was dissected using a glass electrode. Loose-patch voltage-clamp recordings (holding voltage set to "OFF") were performed with a new glass electrode (3-5 $\mathrm{M} \Omega$ ) filled with Ames' medium or whole-cell internal solution. Wholecell voltage-clamp recordings were obtained using glass microelectrodes of 4-5 M $\Omega$ (PC-10 pipette puller; Narishige) filled with an internal solution containing the following (in $\mathrm{mm}$ ): $110 \mathrm{CsMeSO}_{4}, 2.8 \mathrm{NaCl}, 4$ EGTA, 5 TEA-Cl, 4 adenosine $5^{\prime}$-triphosphate (magnesium salt), 0.3 guanosine $5^{\prime}$-triphosphate (trisodium salt), 20 HEPES, 5 QX-314-Br, and 10 phosphocreatine (disodium salt) at pH 7.2 and 290 mOsm. Holding voltages $\left(V_{\mathrm{h}}\right)$ for measuring excitation and inhibition after correction of the liquid junction potential $(-13 \mathrm{mV})$ were $-73 \mathrm{mV}$ or $-3 \mathrm{mV}$, respectively. Signals were acquired using pCLAMP 9 recording software and a Multiclamp 700A amplifier (Molecular Devices), sampled at 20 $\mathrm{kHz}$, and low-pass filtered at $2 \mathrm{kHz}$.

For SAC recordings, retinal slices were prepared as described previously (Oltedal and Hartveit, 2010). OFF SACs were targeted in mGluR2GFP mice (Watanabe et al., 1998).

Visual stimulation. Multiple visual stimuli were used in this study. They are summarized in Table 1 and described below.

Broad-band visible light ranging from 470 to $620 \mathrm{~nm}$ (Fig. 1C) was generated using an OLED display (SVGA + Rev2 OLED-XL; eMagin) displaying custom stimuli created using MATLAB software with the Psychophysics Toolbox as described previously (Huberman et al., 2009). These images were projected to the photoreceptor layer through a $60 \times$ objective (Olympus LUMPlanFl/IR 360/0.90W) with an illumination radius of $218 \mu \mathrm{m}$. Visible light stimuli were presented with both positive and negative contrast at different contrast values. The spectral content of the output of this OLED was significantly reduced for wavelengths $<470$ $\mathrm{nm}$ and therefore activated M-cones and rods, but did not activate UVsensitive cones (Wang et al., 2011) (Table 1). Intensity was controlled by placement of a neutral density filter allowing $\sim 27 \%$ transmission in the stimulation path.

Narrow-band light centered at $375 \mathrm{~nm}$ was generated by an LED (M375L3; Thorlabs) (Fig. 1C) and coupled via a liquid light guide into a digital micromirror device (DMD) projector (CEL5500-fiber; Digital Light Innovations) with custom stimuli generated by MATLAB. Images were projected to the photoreceptor layer via the same $60 \times$ objective. It was assumed that UV light stimuli had a background intensity of 0 be- 
cause in the OFF position the DMD deflects the light from the LED out of the optical path, leading to $100 \%$ contrast stimuli. UV stimulation activated cones containing primarily S-opsin, but also stimulated rods and M-cones via absorption in their beta-bands (Govardovskii et al., 2000; Wang et al., 2011) (Table 1). In a subset of experiments (see Fig. 6), the UV LED was replaced with a green LED centered at $535 \mathrm{~nm}$ (M530L3; Thorlabs), also with $100 \%$ contrast.

To determine the intensities necessary to separate rod, M-cone, and S-cone contributions to ON and OFF responses of DSGCs, a series of flashed spots (200 $\mu \mathrm{m}$ diameter for $2 \mathrm{~s}$ ) with different intensities and spectral profiles were used (Fig. $1 C-F$ ). Recordings were conducted in the ventral retina, where there is a higher concentration of $S$-cones versus $\mathrm{M}$-cones due to the gradient distribution of opsins in the mouse retina (Wang et al., 2011; Baden et al., 2013; Hoon et al., 2014) (Fig. 1C).

UV stimulation at intensities $>1 \times 10^{5}$ photons $/ \mathrm{s} / \mu \mathrm{m}^{2}$ induced robust $\mathrm{ON}$ and OFF responses in DSGCs (Fig. $1 D ; I_{\text {half }}=1.5 \times 10^{5}$ photons $/ \mathrm{s} / \mu \mathrm{m}^{2}$ for ON responses and $1 \times 10^{6}$ photons $/ \mathrm{s} / \mu \mathrm{m}^{2}$ for OFF responses). Dim visible light stimulation at intensities from $5 \times 10^{3}$ to $3 \times 10^{4}$ photons $/ \mathrm{s} / \mu \mathrm{m}^{2}$ induced $\mathrm{ON}$ and OFF responses, whereas intensities $<3 \times 10^{3}$ photons $/ \mathrm{s} / \mu \mathrm{m}^{2}$ induced only ON responses $\left(I_{\text {half }}=\right.$ $1.7 \times 10^{3}$ photons $\left./ \mathrm{s} / \mu \mathrm{m}^{2}\right)$, indicating a higher threshold for activating the OFF rod pathway $\left(I_{\text {half }}=1.4 \times 10^{4}\right.$ photons $/ \mathrm{s} / \mu \mathrm{m}^{2}$; Fig. $\left.1 E\right)$. Visible light at intensities $>3 \times 10^{4}$ photons $/ \mathrm{s} / \mu \mathrm{m}^{2}$ also induced robust $\mathrm{ON}$ and OFF responses mediated by activation of both rods and M-cones. To confirm that $\mathrm{M}$-cones mediated a portion of this response, these measurements were repeated in Gnat $1^{-1-}$ mice that lack the $\alpha$-subunit of rhodopsin transducin and thus lack rod signaling (Calvert et al., 2000). In Gnat ${ }^{-1-}$ mice, visible light evoked responses only at the highest light intensities, indicating activation of M-cones that are present at a lower density in ventral than dorsal retina (Wang et al., 2011; Baden et al., 2013). This was verified as being an M-cone-mediated response by obtaining a similar response threshold after sustained exposure of WT retinas to green light generated by placing a green filter over the microscope condenser $\left(\sim 1.6 \times 10^{6} \mathrm{R}^{\star} / \mathrm{rod} / \mathrm{s}\right.$ for at least $2 \mathrm{~min}$ as used in Wang et al., 2011; data not shown). Note that this protocol was not used to study cone-mediated DS responses due to long-lasting adaptation in DS circuits resulting from photoreceptor bleaching as reported previously by us (Rivlin-Etzion et al., 2012; Vlasits et al., 2014).

To test directional responses of DSGCs, two to three repetitions of a bar (640 $\mu \mathrm{m}$ long $\times 240 \mu \mathrm{m}$ wide) moving in eight different directions across the receptive field of the cells at $0.5 \mathrm{~mm} / \mathrm{s}$ (Fig. $1 B$ ) were presented. The directions were chosen pseudorandomly, spaced at $45^{\circ}$ intervals, and presented every $10 \mathrm{~s}$.

Intracellular fillings and image reconstruction. The dendritic morphologies of the GFP ${ }^{+}$cells shown in Figures $1 B$ and $6 B$ were determined by including $0.05 \mu \mathrm{M}$ Alexa Fluor 594 (Invitrogen) in the intracellular solution after cell-attached or whole-cell voltage-clamp recordings. The dendritic morphologies of dye-injected GFP ${ }^{+}$RGCs or SACs were imaged with the two-photon laser tuned to $800 \mathrm{~nm}$. Images were acquired at $z$ intervals of $0.5 \mu \mathrm{m}$ using the $60 \times$ objective. GFP ${ }^{+}$RGC processes were later reconstructed from image stacks with ImageJ.

Data analysis. Data analysis was performed in IgorPro (WaveMetrics) and ImageJ. For cell-attached recordings, spike information was extracted from the data using the spike feature of Neuromatic and the average spike count in each direction was calculated. In addition, the normalized spike count was calculated by dividing the average spike count in each stimulus direction by the total number of spikes for all directions. The vector summation of these normalized responses yielded a vector (the "vector sum"), the direction of which pointed in the PD of the cell and the magnitude of which gave the strength of tuning (ranging between 0 and 1). For these recordings, the ON and OFF components were taken as the spike responses to the leading (ON) and trailing (OFF) edges of the moving bar. For Figure $1 F$, the total number of spikes in response to each stimulus were normalized by the total number of spikes during the maximum intensity of light stimulation.

For whole-cell voltage-clamp recordings, the peak amplitudes of the ON and OFF components of the postsynaptic currents (PSCs) were calculated as the average around the peak $(100 \mathrm{~ms})$ and averaged over the three repetitions. In the cases where the IPSC amplitudes in response to a PD stimulation were too small to define a peak, the size of these ON and OFF IPSCs was calculated as the average current during the $100 \mathrm{~ms}$ time window surrounding the peak of the ON and OFF IPSCs defined during ND stimulation.

Two measures were used to characterize directional tuning. First, the direction selectivity index (DSI) was calculated, in which values range from 0 to 1 , with 1 indicating greater firing in response to PD stimulation-that is, strong directional tuning. Second, the vector sum of the normalized responses was calculated, in which the length of the vector sum indicated the tuning strength. The DSI for cell-attached responses was calculated as follows:

$$
\text { DSI }=\frac{\text { pref }- \text { null }}{\text { pref }+ \text { null }},
$$

The DSIs for the whole-cell inhibitory and excitatory responses were calculated as per (Poleg-Polsky and Diamond, 2016) as follows:

$$
\text { DSI }=\frac{\text { pref }- \text { null }}{\text { pref }}
$$

where pref is the average response in the stimulus direction closest to the PD and null is the average response in the stimulus direction $180^{\circ}$ opposite.

Statistical analysis. Group measurements, unless otherwise indicated, are expressed as mean $\pm \mathrm{SD}$. $t$ tests were used to compare two groups, paired $t$ test with a Bonferroni's correction for comparisons of tuning properties for ND versus PD stimulation, and one-way ANOVA or repeated-measures ANOVA to compare more than two groups. Details about the statistical tests for different measurements are included in the figure captions.

\section{Results}

\section{Stimulation of S-cone pathway mediates direction selectivity} for ON but not OFF responses

We determined the roles of S-cone, $\mathrm{M}$-cone, and rod signaling in the computation of motion direction by presenting bars of various intensity and wavelength moving in different directions while recording spike responses and synaptic currents from nasal preferring DSGCs transgenically labeled with GFP (Trhr-DSGCs; Fig. 1B; Rivlin-Etzion et al., 2012, 2011). First, we used a UV light stimulus that favored activation of the S-cone pathway, but also activated the rod pathway (Figs. 1C, 2A). We observed strong directional tuning of spike responses in the ON pathway, but weaker directional tuning in the OFF pathway (Fig. 2B).

The weaker directional tuning in the OFF pathway in response to UV stimulation resulted from an increase in action potential firing in response to $\mathrm{ND}$ stimuli, rather than from reduced ability of $\mathrm{PD}$ motion to evoke responses (Fig. $2 B$ ). This increase in firing may be due to an increase in excitation or a decrease in inhibition onto DSGCs. To determine which is the case, we conducted whole-cell voltage-clamp recordings from ON-OFF DSGCs while holding the membrane potential at $-73 \mathrm{mV}$ to measure excitation from $\mathrm{cBCs}$ or at $-3 \mathrm{mV}$ to measure inhibition from SACs (Fig. 2C,D). UV light stimulation produced nondirectionally tuned EPSCs for ON and OFF responses, consistent with previous studies indicating that glutamate release was uniform for moving stimuli (Yonehara et al., 2013; Park et al., 2014). In contrast, UV stimulation evoked IPSCs that were tuned for ON and OFF responses. However, OFF IPSC tuning was weaker due to a significant reduction in ND-evoked IPSC amplitudes compared with ON responses (Fig. 2D).

Strong UV stimulation also activates rods via photon absorption in the rhodopsin's beta-band (Govardovskii et al., 2000; Wang et al., 2011) (Table 1). To isolate the S-cone contribution, we repeated these measurements in Gnat ${ }^{-1-}$ mice, which lack phototransduction in rods (Calvert et al., 2000), but see (Allen et al., 2010). We observed strong tuning of spike responses in the ON pathway, but no directional tuning in the OFF pathway due to increased ND firing (Fig. $2 F$ ). Similar to WT, Gnat $1^{-/-}$DSGCs had untuned EPSCs for 
A WT

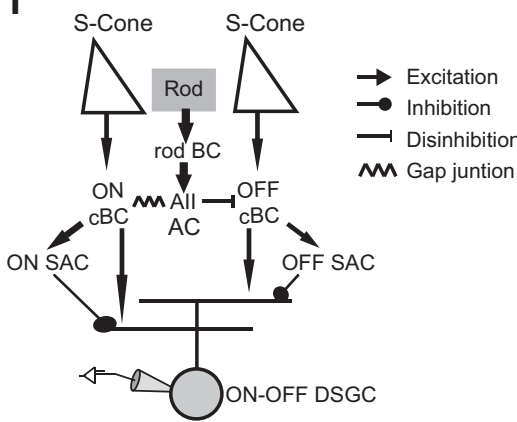

Excitation
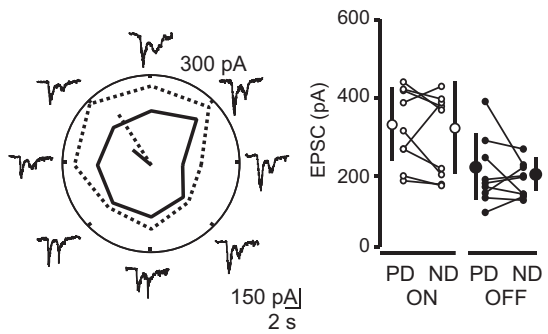

E Gnat1-/-

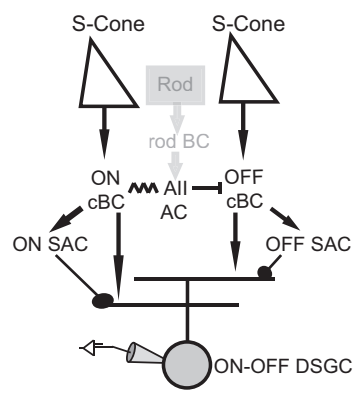

G
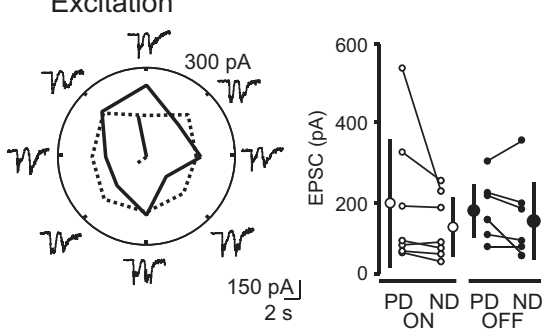

B
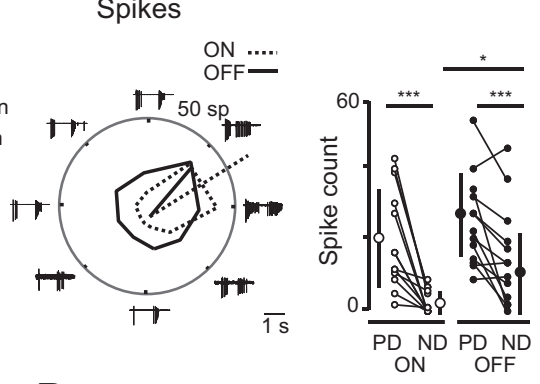

D

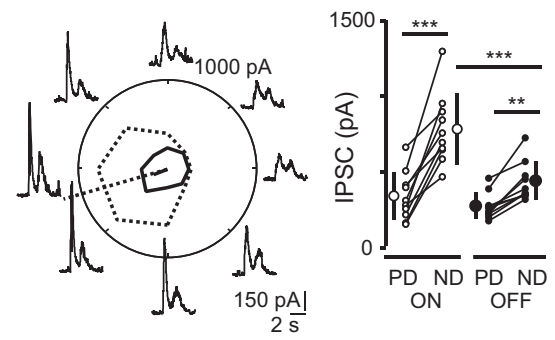

$\mathbf{F}$
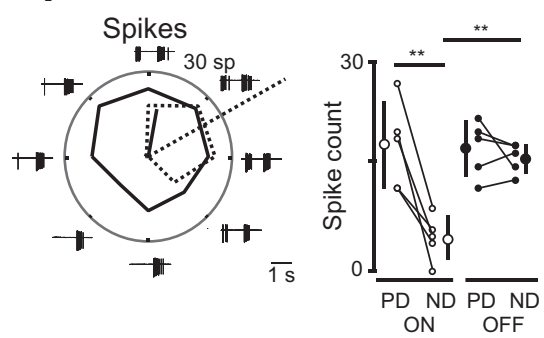

H

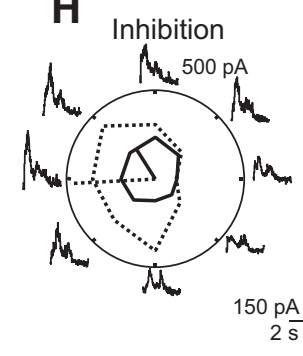

Figure 2. Rod signaling is critical for OFF direction selective tuning with UV stimulation. $\boldsymbol{A}$, Schematic showing activation of the S-cone and rod pathways with UV stimulation in WT mice. Details of stimuli are provided in Table 1. B, Left, Cell-attached recordings from an $0 \mathrm{~N}-0 \mathrm{FF}$ DSGC in response to UV bars moving in eight different directions. Polar plot showing tuning curves and vector sums of the $\mathrm{ON}$ (dashed lines) and OFF (solid lines) responses. Number of spikes (sp) is shown outside the polar plot. Right, Summary of spike counts in response to moving bars in the PD and ND for each DS cell recorded. ON and OFF responses are shown as open and filled circles, respectively. Lines connect spike numbers from the same cell. Error bars indicate $\pm S D$. For both $0 N$ and OFF responses, the spike numbers for PD were significantly different from those for ND. Paired $t$ test for comparing PD versus ND responses within the $\mathrm{ON}$ or $\mathrm{OFF}$ pathway and for comparing $\mathrm{ND}$ responses for $\mathrm{ON}$ versus $\mathrm{OFF}$ stimulation (Bonferroni's correction, $\alpha=4){ }^{*} p<0.013,{ }^{* *} p<0.003,{ }^{* * *} p<0.0003 . \boldsymbol{C}, \boldsymbol{D}$, Left, Example UV-mediated whole-cell voltage-clamp excitatory $\left(\boldsymbol{C} ; V_{\mathrm{h}}=\right.$ $-73 \mathrm{mV}$ ) and inhibitory $\left(\boldsymbol{D} ; V_{\mathrm{h}}=-3 \mathrm{mV}\right)$ currents from a temporally tuned ON-OFF DSGC in response to bars moving in eight different directions. Tuning curve and vector sum as in $\boldsymbol{B}$. Right, Summary of PSC amplitudes in response to moving bars in the PD and ND for each DS cell recorded. $\boldsymbol{E}$, Schematic showing activation of the $S$-cone pathways with UV stimulation in Gnat $1^{-1-}$ mice. $\boldsymbol{F}-\boldsymbol{H}$, Same as in $\boldsymbol{B}-\boldsymbol{D}$, but experiments repeated in Gnat ${ }^{-1-}$ mice to fully isolate S-cone contributions to DSGCS.

both $\mathrm{ON}$ and $\mathrm{OFF}$ responses and well tuned IPSCs for ON responses (Fig. 2G). However, OFF IPSC responses were not directionally tuned due to a significantly reduced inhibition for ND stimulation (Fig. $2 \mathrm{H}$ ). These observations indicate that S-cone stimulation does not strongly activate the OFF SAC but rod stimulation does.
Stimulation of M-cone pathways mediates direction selectivity in both the $\mathrm{ON}$ and $\mathrm{OFF}$ pathways

We next assayed the response of ON-OFF DSGCs to stimulation with visible bars to favor activation of the M-cone pathway. These experiments were performed in Gnat $1^{-1-}$ mice to activate $\mathrm{M}$-cones in the ventral retina exclusively (Fig. 3A). Presenting visible light bars on a black background led to strong directional tuning for both the $\mathrm{ON}$ and OFF pathways in Gnat $1^{-1-}$ retinas (Fig. 3B), indicating that, in contrast to the S-cone pathway, M-cone pathway stimulation is capable of producing robust direction selectivity in both the $\mathrm{ON}$ and OFF pathways. We repeated the voltage-clamp recordings with Gnat1 ${ }^{-1-}$ DSGCs and found symmetric or PD tuned EPSCs (Fig. 3C) and ND-tuned IPSCs (Fig. 3D). Therefore, whereas S-cone and M-cone activation generates excitatory inputs equally to DSGCs, it appears that OFF SACs are more strongly activated for visible stimulation over UV stimulation (Fig. 3E).

\section{ON-mediated signaling contributes to ND inhibition in the OFF pathway}

To explore the interaction between $\mathrm{ON}$ and OFF pathways for visible light stimulation, we used several different stimulation paradigms. First we explored the relative role of rod versus $\mathrm{M}$-cone stimulation. We found that both visible light stimulation at a mesoscopic intensity that favors activation of rods (Fig. $1 F, 2.7 \times$ $10^{4}$ photons $/ \mathrm{s} / \mu \mathrm{m}^{2}$ ) and light stimulation at a photopic intensity that saturates rods and favor activation of $\mathrm{M}$-cones $\left(9.7 \times 10^{5}\right.$ photons $\left./ \mathrm{s} / \mu \mathrm{m}^{2}\right)$ induced robust directional tuning in both $\mathrm{ON}$ and OFF pathways (Fig. $4 A, B$ ). We also assayed the effects of background illumination on the DS tuning responses. Higher background illumination in bright light conditions could limit the rod contribution due to saturation (Eggers et al., 2013; Mazade and Eggers, 2013; Ke et al., 2014). To this end, we reversed the polarity of the stimulus and presented the same dark gray bar on lighter backgrounds at two different contrasts that were above the threshold required for strong DS in guinea pig and rabbit retinas (Lipin et al., 2015). At both low and high contrast, ON and OFF DS tuning remained strong (Fig. $4 C)$, although there was some reduction of DS tuning of the OFF responses with higher background illumination. This indicates that reduction of the rod contribution via saturation decreased OFF directional tuning. Therefore, signaling through the rod pathway also contributes to OFF DS tuning for visible light stimulation, but not as dramatically as for UV stimulation (Figs. 2, 4C). 
To determine whether the OFF M-cone $\mathrm{BC}$ pathway alone was sufficient to drive strong OFF DS responses, we isolated the OFF pathway pharmacologically by blocking rod and $\mathrm{ON}$ cone $\mathrm{BC}$ signaling with the mGluR6 agonist L-AP4 $(20 \mu \mathrm{M})$. During bright visible light stimulation in L-AP4, DSGCs did not spike at the onset of the moving bar. Interestingly, the tuning of OFF responses was reduced significantly, again with increased action potential firing in the ND (Fig. 4D). These data led to the hypothesis that the M-cone contribution to OFF DS tuning may require activation of the ON pathway, influencing OFF DS tuning via a crossover mechanism (Werblin, 2011).

To begin to understand the origin of the ON pathway contributions to direction selectivity in the OFF pathway, we used pharmacological agents to block either the $\mathrm{ON}$ or OFF pathways (Fig. 5A) and measured the synaptic currents onto DSGCs in response to visible light stimulation. To isolate ON signaling to OFF cBCs, we used the kainate receptor antagonist UBP310 $(50 \mu \mathrm{M})$, which strongly inhibits signaling from cones to OFF cBCs (Borghuis et al., 2014; Lindstrom et al., 2014; Puthussery et al., 2014). To isolate cone signaling to OFF CBCs, we used the glycine receptor antagonist strychnine $(2 \mu \mathrm{M})$, which prevents crossover from rod or ON cBC to AII amacrine cell to OFF cBC signaling (Demb and Singer, 2012), (Manookin et al., 2008; Molnar et al., 2009).

We first confirmed the ability to block all OFF pathway signaling using a combination of these pharmacological agents by conducting whole-cell voltage-clamp recordings of excitatory currents from DSGCs in response to a flashing spot of bright visible light. OFF signaling was partially blocked by UBP310 (Fig. 5B), indicating that excitatory OFF signals onto DSGCs are partly mediated by cone to OFF CBC synapses. The remaining response was completely eliminated by adding strychnine (Fig. 5B), indicating that the residual excitation observed in UBP310 resulted from disinhibition of the glycinergic amacrine to OFF $\mathrm{CBC}$ synapse. These results support a previous finding in mice in which both excitatory currents onto delta-OFF RGCs and glutamate release from OFF bipolar cells were strongly inhibited by a combination of kainate and glycine receptor blockers (Borghuis et al., 2014), although some OFF cBCs also express AMPA-R (Puller et al., 2013; Ichinose and Hellmer, 2016). Notably, UBP310 produced a delayed onset of the OFF response $(43.6 \pm 10.5 \mathrm{~ms}, n=6)$. The source of this delay in the AII amacrine to OFF $\mathrm{CBC}$ pathway is not known, but has been reported previously (Manu and Baccus, 2011).

To determine the relative contributions of the ON pathways to OFF DS during bright visible light stimulation, we recorded inhibitory currents in DSGCs in response to moving bars. Removing the OFF $\mathrm{cBC}$ contribution with UBP310 decreased the
B
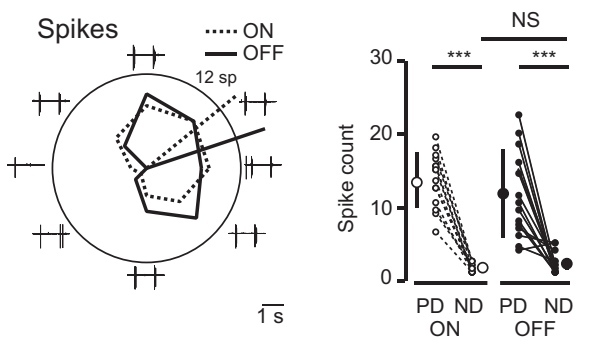

D
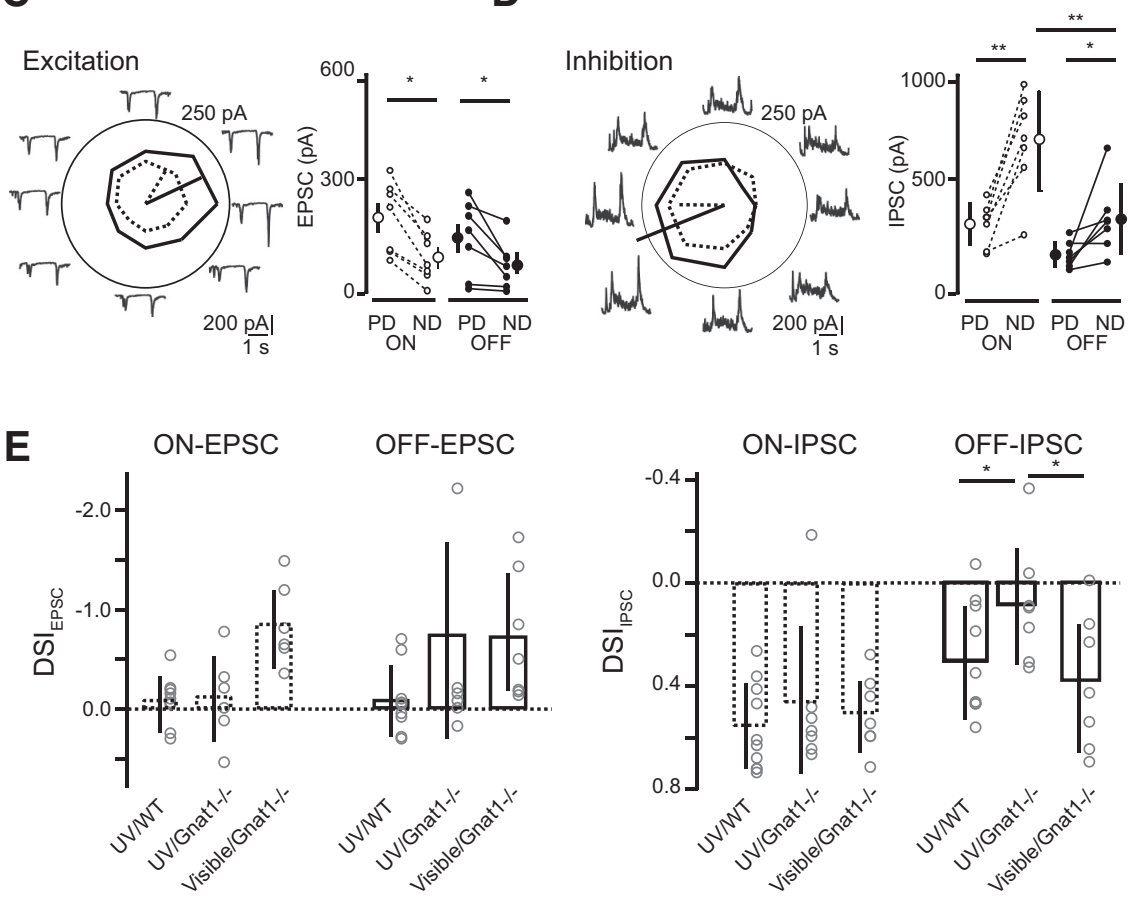

Figure 3. Strong ON and OFF direction selective tuning in the absence of rod signaling with visible light stimulation. $\boldsymbol{A}$, (dashed lines) and OFF (solid lines) responses. Number of spikes (sp) is shown outside of the pola

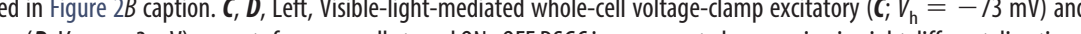
Right, Summary of PSC amplitudes in response to moving bars in the PD and ND for each DS cell recorded. $\boldsymbol{E}$, Summary data for PSC DSI for UV stimulation (Fig. 2) and visible light stimulation. Each circle is an individual cell. Error bars indicate \pm SD. One-way ANOVA, Tukey's post hoc test, ${ }^{*} p<0.05$.

amplitude of the OFF inhibitory currents for both PD and ND stimulation (Fig. 5C), but actually increased the inhibitory OFF DSI. In contrast, removing ON pathway contributions with strychnine decreased the amplitude of the OFF inhibitory current only for ND stimulation (Fig. 5D), thus decreasing the inhibitory OFF DSI. In addition, blocking both rod and cone ON pathways with L-AP4 also decreased the amplitude of the OFF inhibitory current solely for ND stimulation (Fig. $5 E$ ), thus decreasing the inhibitory OFF DSI. In contrast, strychnine had no effects on the ON inhibitory tuning (IPSC: DSI ${ }_{\text {control }}=0.53 \pm 0.18$; DSI $_{\text {strychnine }}=0.70 \pm 0.07 ; n=6 ; p=0.12$, data not shown), indicating that, under our stimulus conditions, glycinergic inhibition did not affect the direction selectivity of GABA release from ON SACs. Therefore, ON contributions to the OFF path- 


\section{A Bright visible light}
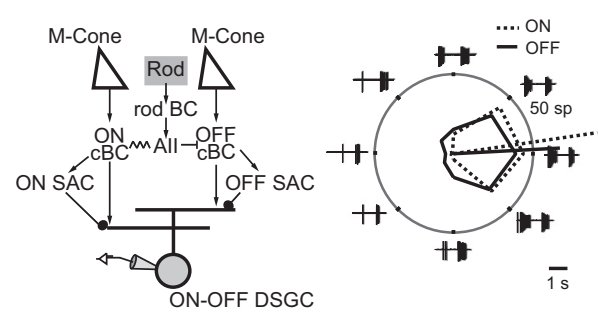

\section{Dark bar}
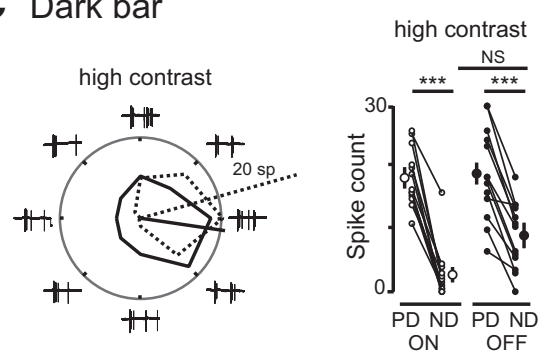

B Dim visible light
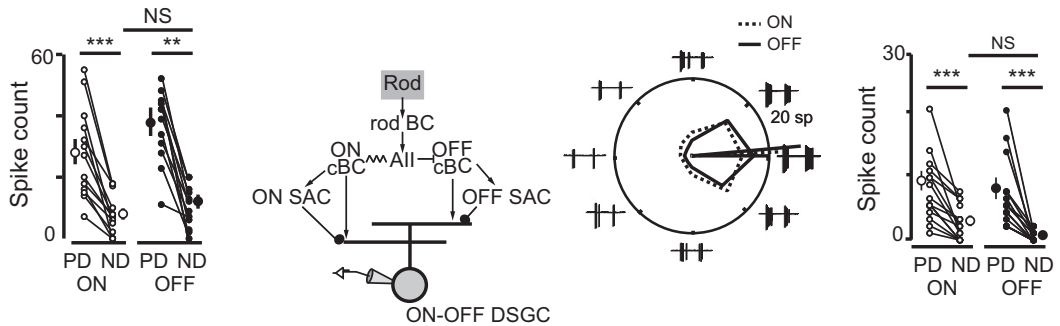

D WT-AP4 (OFF only)
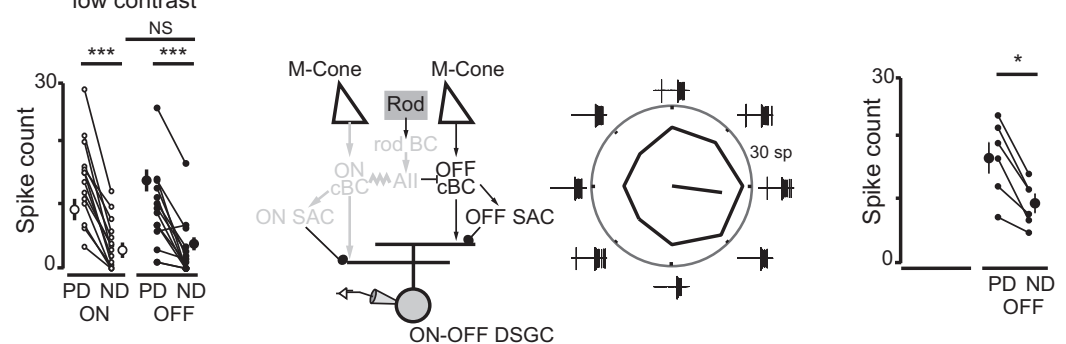

F
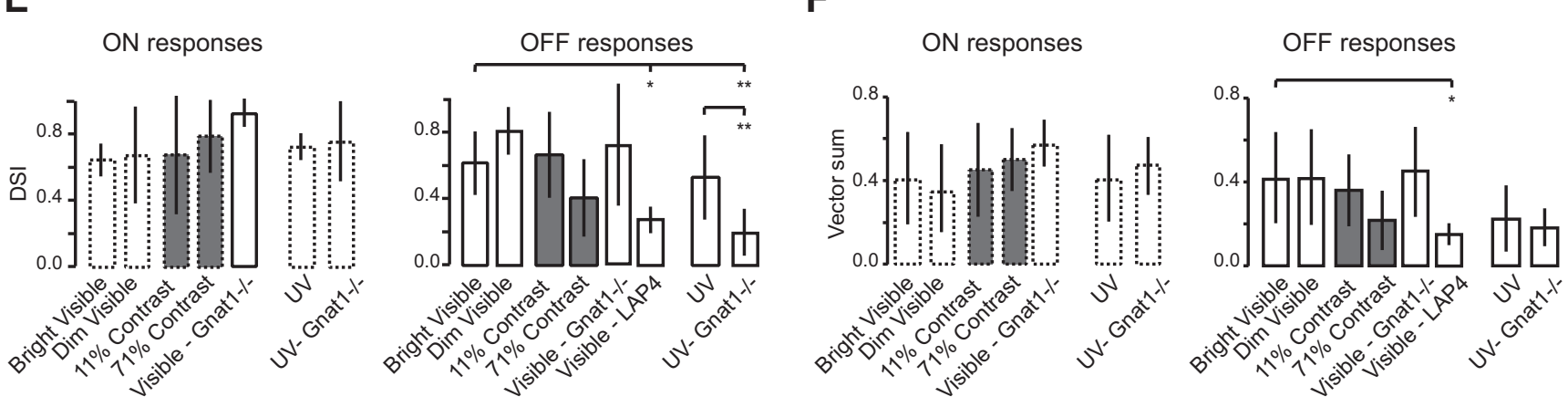

Figure 4. ON signaling is critical for OFF direction selective tuning with visible light stimulation. $\boldsymbol{A}, \boldsymbol{B}$, Left, Schematic showing activation of the rods and M-cones with bright visible light $(\boldsymbol{A})$ or rods with dimmer visible light $(\boldsymbol{B})$ stimulation in WT mice. Details of all stimuli are provided in Table 1. Right, Cell-attached recordings from an 0N-0FF DSGC in response to bars moving in eight different directions (as described in Fig. $3 B$ ). Paired $t$ test was used as described in Figure $2 B$ caption. $\boldsymbol{C}$, DS responses to stimulation using bars with the opposite polarity of those shown in $\boldsymbol{A}$ and $\boldsymbol{B}$; that is, a dark gray bar on a lighter gray background. $D$, Left, Schematic showing activation of brighter visible stimulation in WT mice in the absence of ON cBC and rod BC signaling. Right, DS responses to stimulation with bright visible light in WT retina in the presence of L-AP4 (20 $\mu \mathrm{m})$. There were no detectable ON responses. $\boldsymbol{E}, \boldsymbol{F}$, Summary of average DSIs $(\boldsymbol{E})$ and vector sums $(\boldsymbol{F})$ for $0 \mathrm{~N}(/$ eft $)$ and OFF (right) responses in all light conditions shown in $\boldsymbol{A}-\boldsymbol{D}$ and Figures 1 and 2 . Error bars indicate \pm SD. One-way ANOVA, Tukey's post hoc test, ${ }^{*} p<0.05,{ }^{* *} p<0.01$, and ${ }^{* * *} p<0.01$ compared with the bright visible responses. Student's $t$ test used to compare the UV and UV-Gnat ${ }^{-1-}$ population.

way via crossover glycinergic signaling preferentially increases ND inhibition. Because OFF directional tuning was normal in Gnat $1^{-1-}$ mice in response to visible light stimulation (Fig. $3 B$, $4 E$ ), we assume that this $\mathrm{ON}$ contribution was via the $\mathrm{ON}$ cone pathway. The basis of this asymmetric action of strychnine on PD versus ND stimulation is not understood, but may be due to differences in integration of $\mathrm{cBC}$ inputs by SACs (Vlasits et al., 2016). Together, these data indicate that $\mathrm{ON}$ signaling in visible light is crucial for robust directional tuning in the OFF pathway. Note this is in contrast to recordings in rabbit retina, in which the presence of L-AP4 did not reduce directional tuning in the OFF pathway (Kittila and Massey, 1995), indicating that there might be a species difference (Ding et al., 2016).

\section{ON signaling contributes significantly to excitation of OFF SACs}

Because SACs provide inhibition to DSGCs and OFF inhibition onto DSGCs is less tuned when the ON pathway is blocked (Figs. $4 D-F, 5 D, E$ ), we hypothesized that the ON pathway contributes strongly to excitation of OFF SACs. To test this hypothesis, we conducted voltage-clamp experiments on $\mathrm{GFP}^{+}$OFF SACs in retinal slices taken from ventral retina and held these SACs at $-73 \mathrm{mV}$ to isolate excitatory currents in response to flashes of light. We first used a green LED for visual stimulation $\left(6.4 \times 10^{5}\right.$ photons $/ \mathrm{s} / \mu \mathrm{m}^{2}$ ) that activates both $\mathrm{M}$-cones and rods (Fig. $6 \mathrm{~A}$, Table 1). To calculate the ON pathway contribution to excitation of OFF SACs, we subtracted from the control current the excitatory current in the presence of strychnine, which blocks ON pathway input to the OFF pathway (Fig. $6 A, C$ ). Strychnine significantly reduced the amplitude of the excitatory current in response to green light stimulation. Indeed, $\mathrm{ON}$ pathway signaling provides $\sim 60 \%$ of the total input $(58 \pm 8.3 \%, n=5$, Fig. $6 C, D$ ) to OFF SAC excitation in response to stimulation that activates both rods and M-cones. We also found that the ON pathway contribution onto OFF SACs is delayed from the beginning of the OFF stimulus by $37 \pm 26 \mathrm{~ms}(n=8)$, similar to that observed in DSGCs

(Fig. 5B).

Next, we repeated the experiment using UV stimulation. Similar to visible stimulation, we observed a reduction in the ampli- 
tude of the EPSC recording in OFF SACs in the presence of strychnine (Fig. 6C,D). The ON pathway contribution via UV stimulation was notably weaker than for visible stimulation $(27 \pm 9 \%, n=5)$, indicating that the crossover inputs provided by $\mathrm{S}$-cones and rods during UV stimulation were weaker than those provided by $\mathrm{M}$-cones and rods during green stimulation. Therefore, our data indicate that the ON pathway contributes to OFF DSGC tuning by providing strong excitatory drive to OFF SACs.

ON contribution to DS is established at eye opening, whereas OFF contribution matures later in development for UV stimulation

Direction selectivity is present at eye opening, displaying DS tuning comparable to that in adults (Elstrott et al., 2008; Wei et al., 2011; Yonehara et al., 2011; Chen et al., 2014). Although evidence suggests that ON circuits mature before OFF circuits (Hoon et al., 2014), the exact time when these pathways become fully developed is unknown. Therefore, we used the strong ON pathway contribution to OFF directional tuning to determine how the different crossover pathways that contribute to direction selectivity emerge during development.

We first used immunofluorescence to characterize the development of the distribution of cone photoreceptors that express S-opsin or M-opsin (Fig. 7 $A, B$ ) because of the chromatic differences in ON to OFF crossover signaling that we observed in the adult retinas (Figs. 4, 6). We first characterized S-opsin-expressing cones across development. Adult retinas displayed a dorsal-ventral (D-V) gradient for S-opsin-expressing cones (Röhlich et al., 1994; Applebury et al., 2000), in which the ventral retina has a high density of S-opsin-expressing cones, whereas the dorsal retina has only a few of them. P13 mouse retinas also exhibited a D-V gradient of S-opsin expression, but it was less steep than that in adult retinas. Interestingly, P11 retinas showed little or no such gradient, indicating that the S-opsinexpressing cone distribution dramatically changes around eye opening (P13). Indeed, the density of S-opsin-expressing cones in ventral retina increased 1.7-fold from $\mathrm{P} 11$ to $\mathrm{P} 13$, and this density in dorsal retina decreased threefold from P13 to adult (Fig. 7C; Roberts et al., 2006).

We then characterized M-opsin expression across development (Fig. 7B). Similar to previous studies (Breuninger et al., 2011; Baden et al., 2013), M-opsin-
A

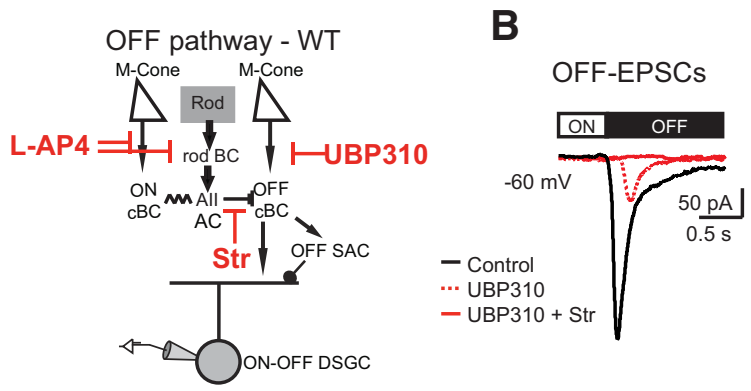

C
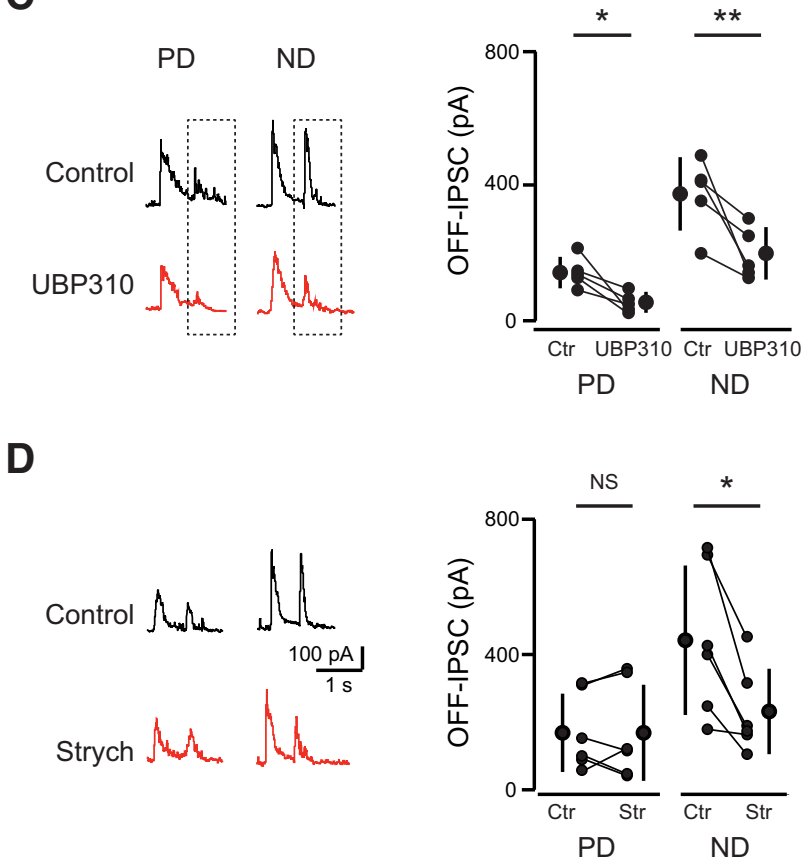

$\mathbf{E}$

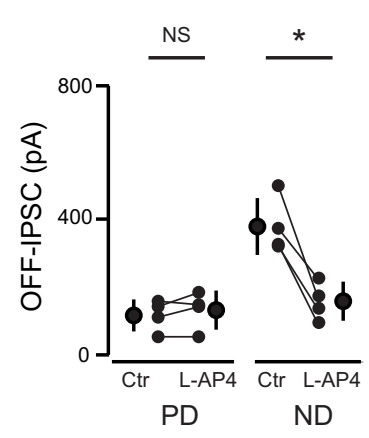

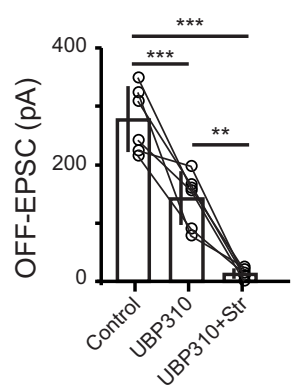
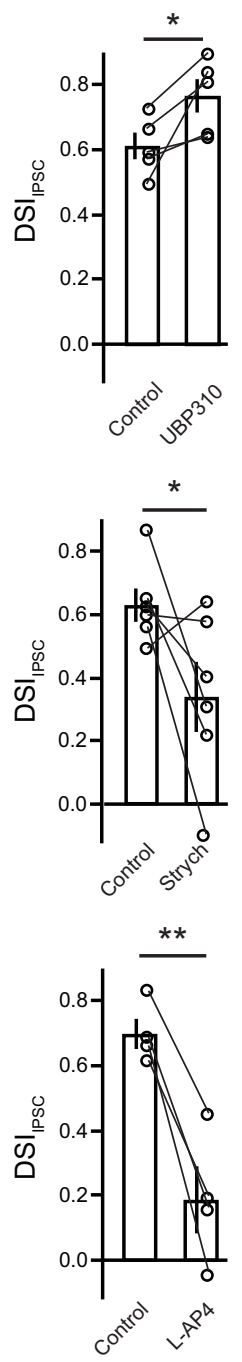

Figure 5. ON signaling improves OFF direction selectivity of inhibitory currents. $A$, Schematic of circuits that mediate OFF responses originating in rods or cones in bright visible light. $\mathrm{OFF} C B C$ s receive excitatory inputs directly from cones or indirectly from rod-BCs and $\mathrm{ON} C B C s$ through disinhibition via glycinergic amacrine cells. Crossover inputs from $0 \mathrm{~N}$ signaling were isolated by using the kainate receptor antagonist UBP310 (50 $\mu \mathrm{M}$; red, dashed); direct OFF signaling was isolated either by using the glycinergic antagonist strychnine $(2 \mu \mathrm{M})$ or the mGluR6 agonist L-AP4 $(20 \mu \mathrm{M})$. B, Left, DSGC excitatory OFF responses to a spot of bright visible light (offset, bar at top) measured using whole-cell recording $\left(V_{\mathrm{h}}=-73 \mathrm{mV}\right)$ in control (black), UBP310 (red, dotted), and UBP310 + strychnine (red, solid). Right, Summary results of the OFF current amplitudes for the three conditions ( $n=6$ DSGCs from 3 retinas). Repeated-measures ANOVA, ${ }^{* *} p<0.01,{ }^{* * *} p<0.001$. Error bars indicate \pm SD. C, Left, IPSCS recorded in DSGCs in response to PD or ND stimulation before (top) and after pharmacologically blocking the OFF cone pathway with UBP310 (bottom). OFF responses are indicated by dotted boxes. Middle, Summary of OFF inhibitory currents in response to PD and ND stimulation in control and after blockade. Lines connect values from the same cell. Right, DSI for IPSCs before and after UBP310. Paired $t$ test, ${ }^{*} p<0.05,{ }^{* *} p<0.01$. Circle and error bars indicate mean $\pm S D . \boldsymbol{D}, \boldsymbol{E}$, Same as $($ for glycinergic antagonist strychnine $(2 \mu \mathrm{m} ; \boldsymbol{D})$ or the mGluR6 agonist L-AP4 $(20 \mu \mathrm{m} ; \boldsymbol{E})$. 
A

UV light or green light - WT

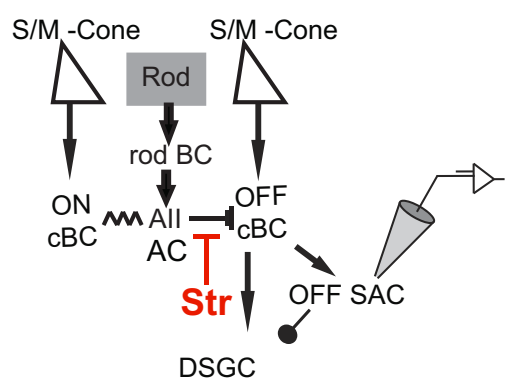

C

\section{Green light}
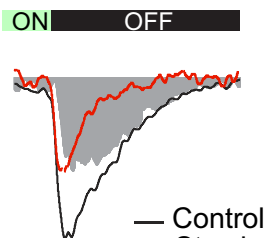

- Control

ON contribution

\section{Bright UV light}
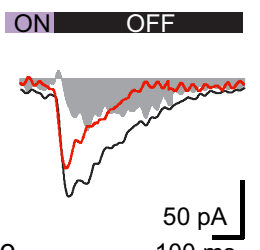

B
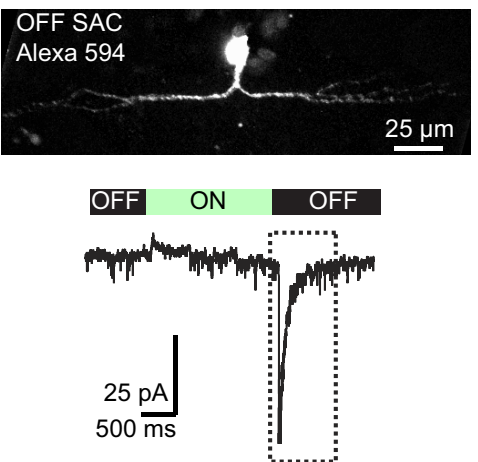

D

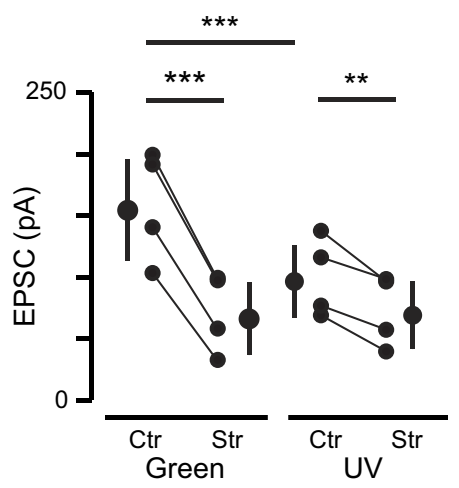

Figure 6. The ON pathway contributes significantly to excitation of OFF SACS. $A$, Schematic of circuits that mediate OFF responses originating in rods or cones. $\boldsymbol{B}$, Top, Side view of a slice from ventral retina showing the dendritic stratification of an OFF SAC filled with Alexa-Fluor 594. Bottom, Excitatory OFF response of OFF SACs to a $2 \mathrm{~s}$ flash of green light. For recordings, OFF SACs were held at $-65 \mathrm{mV}$ and light stimulation was focused on the photoreceptor layer of the retinal slice. Dotted box indicates the area over which OFF responses were analyzed in $\boldsymbol{C}$ and $\boldsymbol{D}$. $\boldsymbol{C}$, Whole-cell voltage-clamp recordings of excitatory currents from an OFF SAC in control conditions (black) and after strychnine application (red) in response to flashes of green (left) or UV light (right). Filled areas represent the crossover contribution of the current, calculated by subtracting the current in strychnine from that in control. D, Summary of the EPSC amplitudes in OFF SACs before and after strychnine application in response to green (left) or UV stimulation (right; $n=5$ OFF SACs from 3 retinas). Paired $t$ test, ${ }^{*} p<0.05,{ }^{* *} p<0.01,{ }^{* * *} p<0.001$. Circle and error bars indicate mean \pm SD.

expressing cones were found in both the ventral and dorsal regions of adult retinas. This pattern of $\mathrm{M}$-opsin expression was also present in younger animals. Unlike with S-opsin expression, M-opsin-expressing cones did not exhibit significant changes in density during development, maintaining the same level of expression from P11 to P30. These data indicate that S-opsinmediated signaling may reach maturity later than M-opsinmediated signaling (Fig. 7C).

We next characterized the maturation of $\mathrm{ON}$ and $\mathrm{OFF}$ inputs onto DSGCs by conducting cell-attached recordings from GFP ${ }^{+}$ DSGCs in ventral retinas isolated from P11 and P13 mice (Figs. $8 A, B)$. Visible light $\left(3 \times 10^{4}\right.$ photons $\left./ \mathrm{s} / \mu \mathrm{m}^{2}\right)$ evoked DS responses at eye opening (P13) and even $2 \mathrm{~d}$ before eye opening (P11) for both ON and OFF responses (Fig. 8B, left), with spike rates comparable to those observed for this light intensity in the adult. Although the average DS tuning was weaker in young animals than in adults, the variance was quite large at all ages. This early development of direction selectivity parallels the early development of mature M-opsin expression (Fig. 7). In contrast, UV light produced DS responses for the ON pathway at P11 and P13, but very weak DS responses for the OFF pathway around eye opening (Fig. $8 A, B$ ). Unlike in the adult, the weak OFF DS tuning around eye opening was due to an decrease in spiking activity in response to $\mathrm{PD}$ stimulation, rather than increased spiking to ND stimulation (Fig. $8 A$, right). Indeed, a small but significant reduc- tion in PD-evoked spiking was also observed for $\mathrm{ON}$ responses around eye opening compared with the adult (Fig. $8 A$, right).

Because the level of S-opsin expression seen in ventral retina at $\mathrm{P} 13$ appears to be mature (Fig. 7), we hypothesized that the reduced firing in response to PD stimulation of DSGCs at P13 was due to weaker excitation from the OFF bipolar cell pathway. Indeed, whole-cell voltage-clamp experiments at $\mathrm{P} 13$ in response to $\mathrm{UV}$ stimulation (Fig. $8 \mathrm{C}$ ) revealed that, at P13, OFF EPSCs and OFF IPSCs in response to $\mathrm{PD}$ and ND stimulation at P13 were significantly smaller than those of adults (Fig. 2), indicating that DSGCs receive less excitatory and inhibitory input from UV stimulation in early development than they do in adulthood. Moreover, OFF EPSCs recorded in DSGCs evoked in response to bright UV stimulation in $\mathrm{P} 13$ mice were unaffected by the presence of the kainate receptor antagonist UBP310, but completely blocked by the presence of strychnine (Fig. $8 D$ ). This is in sharp contrast to the adult, in which UBP310 strongly inhibits the excitatory current (Fig. $5 B$ ), and is consistent with observations that kainate receptors on OFF cBCs do not reach maximal expression levels in the outer plexiform layer until P20 (Hack et al., 2002). Therefore, around eye opening, OFF responses to UV light in DSGCs rely primarily on signals originating in the ON pathway.

Based on our results in the adult (Fig. 5), we would predict that a circuit relying exclusively on crossover inputs originating in the ON pathway would have increased direction selectivity rather than decreased. However, crossover input during UV stimulation in the adult accounts for $\sim 25 \%$ of total excitatory input (Fig. $6 D$ ). Therefore, we hypothesize that, during development, a reliance on crossover input results in weak excitation that does not drive spiking during PD motion and thus leads to a loss of DS. In support of this hypothesis, the subset of P13 DSGCs that had robust spiking in the $\mathrm{PD}$ displayed more directional tuning (Fig. 8A, right). The comparison between UV and visible stimulation, the latter of which appears to be sufficient for exciting DSGCs at eye opening, is discussed below.

\section{Discussion}

Our findings indicate that signaling through the ON pathway, initiated by both rods and cones, is crucial for generating DS responses in the OFF pathway. Retinas lacking rod signaling $\left(\mathrm{Gnat}^{-/-}\right.$) show strong directional tuning in the ON pathway for both visible and UV light stimulation, but reduced directional tuning in the OFF pathway for only UV stimulation. For visible light stimulation, blockade of the ON pathway with L-AP4 reduced OFF directional tuning, indicating that $\mathrm{ON}$ inputs originating in the rod or M-cone pathway, contribute to OFF directional tuning. This lack of OFF directional tuning when the OFF pathway is isolated correlates with decreased inhibition onto 
A

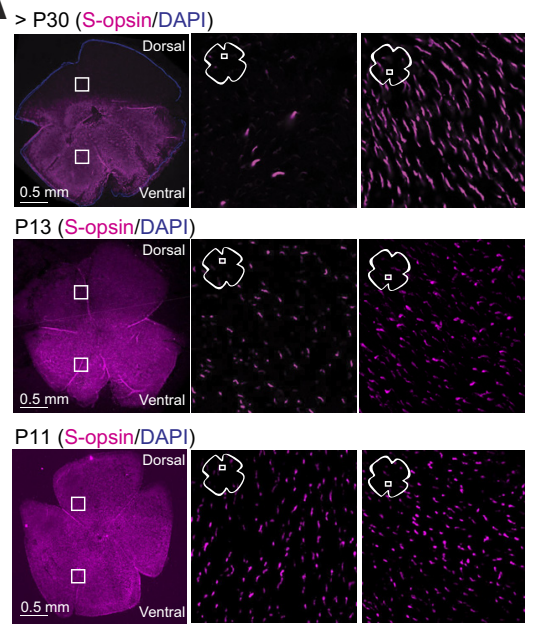

B

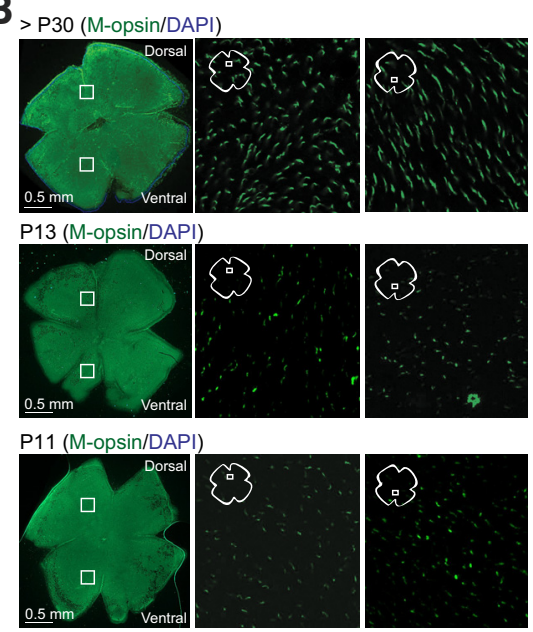

C

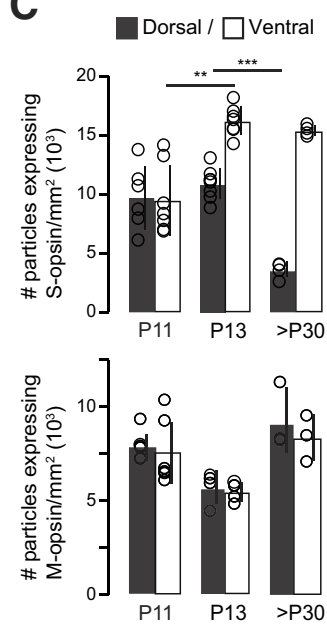

Figure 7. Development of S-opsin-expressing cones in dorsal and ventral retina. $\boldsymbol{A}$, Whole-mount retinas from an adult (top), P13 (middle), and P11 (bottom) mouse stained for S-opsin. Left, Whole retina epifluorescent image. Middle, Higher-magnification confocal image of dorsal region indicated by inset on the left. Right, Higher-magnification confocal image of ventral region indicated by inset on the left. $\boldsymbol{B}$, Same as $\boldsymbol{A}-\boldsymbol{C}$, but with M-opsin staining. $\boldsymbol{C}$, S-opsin (top) and M-opsin (bottom) expression in the dorsal (black) and ventral (white) retina for P11, P13, and $>$ P30 mice. Error bars indicate \pm SD. One-way ANOVA, Tukey post hoc test, ${ }^{*} p<0.05,{ }^{* *} p<0.01,{ }^{* *} p<0.001$.

DSGCs in response to ND stimulation under ON pathway blockade, indicating a weaker activation of OFF SACs. Consistent with this, ON-mediated signaling contributes to the excitation of OFF SACs. Studying the emergence of ON contributions to OFF DS tuning through development showed that, for UV stimulation, ON inputs to the OFF pathway mature earlier than direct activation of OFF bipolar cells. Together, our data indicate that the interactions between $\mathrm{ON}$ and OFF pathways are critical for the robust computation of DS across light intensities, with crossover inputs providing the dominant contribution during development.

ON and OFF pathways contribute to OFF direction selectivity It is well established that directional tuning of DSGCs is shaped by GABAergic inhibition mediated by SACs that increase their numbers of null-side inhibitory synapses asymmetrically during the second postnatal week (Wei et al., 2011; Morrie and Feller, 2015). Here, we propose that asymmetric inhibition onto ONOFF DSGCs requires ON signaling originating in the rod and cone pathways to activate OFF SACs strongly during ND stimulation. Three lines of evidence support this hypothesis. First, visual stimulation in pharmacological conditions that maintained the OFF pathway but suppressed the ON pathway led to robust spiking activity during the OFF response to ND stimulation and therefore reduced directional tuning (Fig. 4). Second, visual stimulation in conditions that maintained ON pathway signaling led to stronger inhibitory currents onto DSGCs during the OFF response to ND stimulation than inhibitory currents induced by stimulation of the OFF pathway alone (Fig. 5). Third, conditions that maintained ON pathway signaling led to stronger excitatory inputs onto OFF SACs than stimulation that isolated the OFF pathway (Fig. 6).

These results lead us to speculate about which of the potential circuit motifs involving activation of the ON pathway and convergence onto $\mathrm{OFF} \mathrm{cBCs}$ could be the source of excitation onto OFF SACs (Fig. 1A). For an example, we will consider the rod circuit for which the inputs to the OFF pathway are known to occur via the glycinergic AII amacrine cell. In this case, the most likely circuit motif is rod $\rightarrow$ rod bipolar cell $\rightarrow$ AII amacrine $\rightarrow$ OFF cBCs. Light stimulation hyperpolarizes rods, which in turn depolarizes rod BCs and AII amacrine cells, providing a tonic inhibition onto OFF cBCs. In this scenario, when the light intensity decreases, the relief of this inhibition depolarizes the OFF cBC (Molnar et al., 2009; Werblin, 2010). This motif would also apply to $\mathrm{ON}$ cBC pathways, in which, during light offset, cones then hyperpolarize $\mathrm{ON}$ cBCs and AII amacrine cells (via a gap junction), which relieves the tonic inhibition onto OFF cBCs. Both pathways are sensitive to L-AP4 (rod BC or ON cBC; Fig. $4 D$ ) and strychnine (AII amacrine $\rightarrow$ OFF cBC; Fig. $5 A, D$ ). A third circuit has been described previously for ON-OFF DSGCs (DeVries and Baylor, 1995), in which rods coupled to cones via a gap junction provide sign-preserving inputs to OFF cBCs. However, this motif does not appear to be plausible because of the observed sensitivity of OFF DS responses to L-AP4, which blocks signaling in $\mathrm{ON} \mathrm{cBC}$ and rod bipolar cell pathways (Fig. 4D) and the persistence of DS IPSCs in the presence of kainate receptor antagonists (Fig. 5C)

Recently, it was proposed that two types of OFF cBCs with different release kinetics form synapses onto distinct sections of the SACs: sustained BC2 synapses onto the proximal part of the SAC dendritic arbor and transient BC3 synapses onto more distal segments, an arrangement critical to the direction-dependent release of GABA from OFF SAC processes (Kim et al., 2014). These two types of OFF BCs are thought to get unequal inputs from AII amacrine cells, with $\mathrm{BC} 2$, but not $\mathrm{BC} 3$, receiving robust rodmediated inhibitory inputs that likely come from the rod-AII amacrine pathway (Mazade and Eggers, 2013). This arrangement suggests that rod input via AII amacrine cells could provide the BC2 modulation necessary for direction selectivity in SACs. However, further experiments are necessary to establish whether the rod or $\mathrm{ON} \mathrm{CBC}$ pathway provides the dominant input to $\mathrm{BC} 2$ and if activation of both BC types is required for SAC DS (Kim et al., 2014; Ding et al., 2016). Interestingly, both BC2 and BC3 receive S-cone and $\mathrm{M}$-cone inputs (Euler et al., 2014), consistent with these $\mathrm{cBCs}$ providing sites for crossover inputs from both chromatic pathways.

\section{Late development of OFF S-cone pathway}

DSGC direction selectivity is present at eye opening, with tuning comparable to adult DSGCs (Elstrott et al., 2008; Wei et al., 2011; 
A

$\mathrm{P} 13$

UV stimulaton

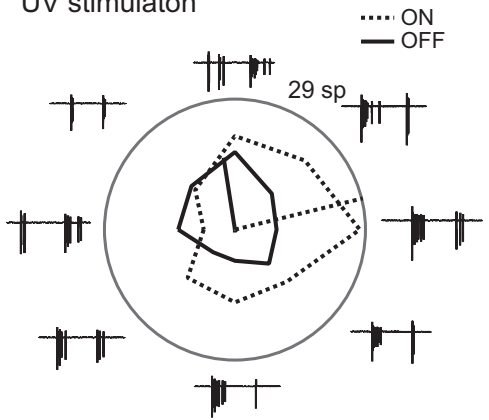

B

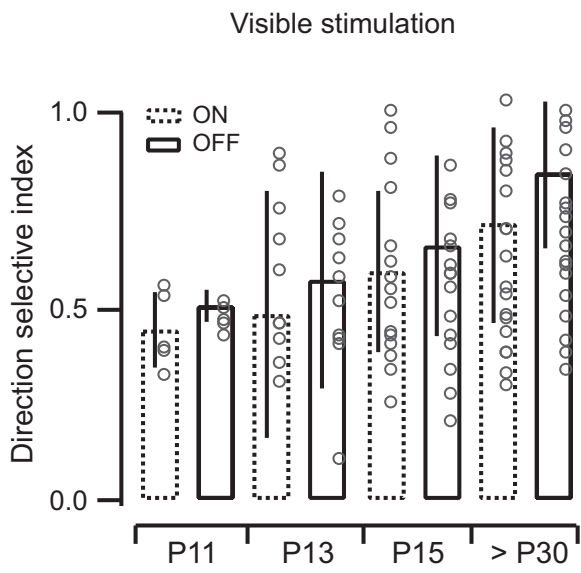

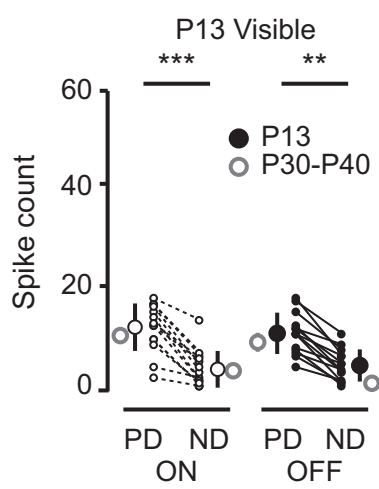

P13 UV
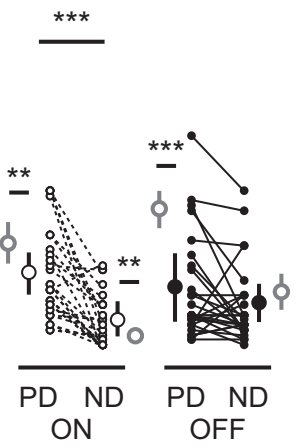

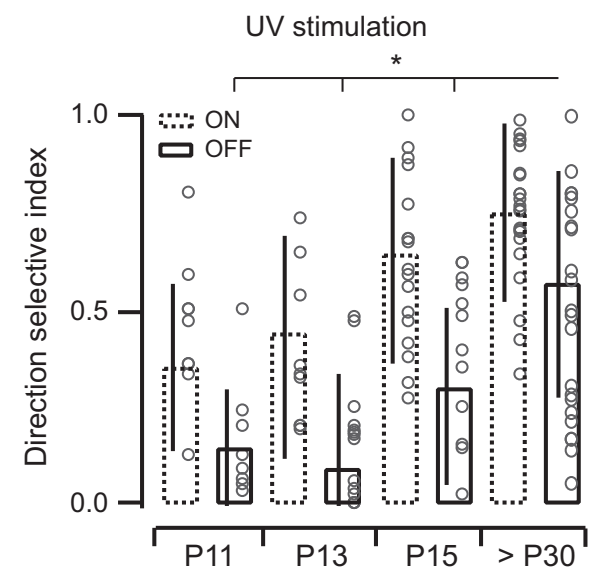

C
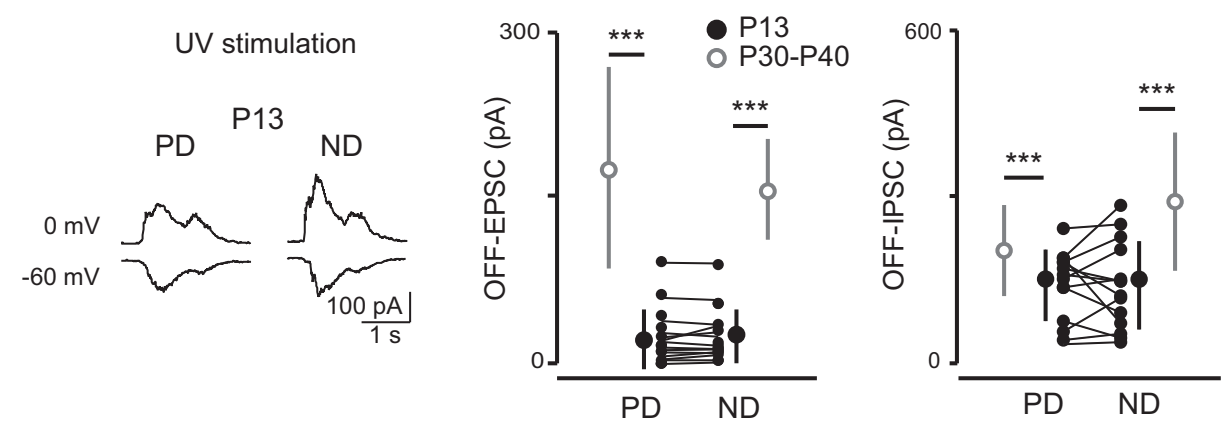

D
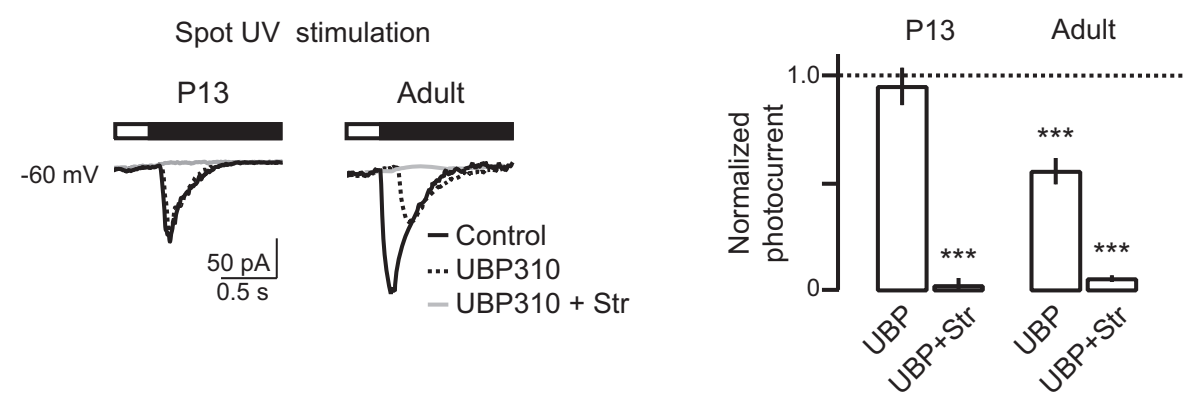

Figure 8. Rod-and cone-mediated pathways follow different developmental time courses. $A$, Left, Cell-attached recordings from a P13 ON-OFF DSGC in response to bright UV bars moving in eight different directions $\left(\sim 5.1 \times 10^{5}\right.$ photons $/ \mathrm{s} / \mu \mathrm{m}^{2}$ ). Polar plot shows tuning curves and vector sums of ON (dashed line) and OFF (solid line) responses. Right, Spike count for ON (left) and OFF (right) responses when using dim visible or UV light. Error bars indicate \pm SD. Paired $t$ test for comparing PD versus ND responses within the ON or OFF pathway, one-way ANOVA, Tukey post hoc test compared with $>\mathrm{P} 30,{ }^{*} p<0.5,{ }^{* *} p<0.1,{ }^{* * *} p<0.01$. B, Summary of DSI for ON (dashed) and OFF (solid) responses for dim visible stimulation (left) or UV stimulation (right). Error bars indicate \pm SD. One-way ANOVA, Tukey's post hoc test, ${ }^{*} p<0.05$ compared with $>$ P30.C, Left, Whole-cell voltage-clamp recordings of excitatory (bottom traces) and inhibitory (top traces) PD and ND currents from a DSGC at P13 while stimulating with bright UV light. Right, EPSC and IPSC amplitudes for OFF responses to bright UV stimulation in P13 retinas (black). Shown are average P30 -P40 data (gray) from Figure 3. Circle and error bars indicate mean \pm SD. One-way ANOVA, Tukey's post hoc test, ${ }^{*} p<0.05$ compared with $>P 30$. D, Left, Whole-cell voltage-clamp recordings of $0 F F$ excitatory currents in response to stationary spots of brightUV stimulation (top bar) for P13 and P30-P40 DSGCs. Recordings were conducted in control (solid black), UBP310 (dotted), and UBP310 + strychnine (gray) conditions. Right, Ratio of OFF EPSCs in drug to control EPSCs in P13 and P30-P40 ON-OFF DSGCS. Error bars indicate \pm SD. One-way ANOVA, Tukey's sosthoc test, ${ }^{* * *} p<0.001$ compared with control. 
Chen et al., 2014). Our results reveal early DS tuning in the ON pathway in response to both visible light and bright UV light. However, we found that, at eye opening, only visible light stimulation led to robust DS tuning in the OFF pathway, whereas UV light did not (Fig. 8). Because S-opsin is expressed robustly at these early ages (Fig. $7 A-C$ ), we hypothesize that the slower development of DS responses in the OFF pathway may be due to weak synaptic connections between cones and OFF cBCs. Two lines of evidence are consistent with this hypothesis. First, we observed no effect of kainate receptor antagonists on conemediated OFF excitatory currents in DSGCs of young retinas (Fig. $8 D$ ), whereas these antagonists inhibited light-evoked responses from OFF cBCs in P30-P40 mice (Fig. 5B). Second, kainate glutamate receptors associated with $\mathrm{OFF} \mathrm{cBCs}$ are first detected in the outer plexiform layer at P10 and do not reach full maturation until P20 (Hack et al., 2002; also see review by Hoon et al., 2014), whereas metabotropic glutamate receptors associated with ON BCs are detected as early as P5.

We postulate that a lack of excitation in the OFF pathway led to reduced firing in the PD and therefore less DS tuning (Fig. 8A, right). However, there are two surprising aspects to this finding. First, this is in contrast with the adult retina, in which crossover inputs from the ON pathway are crucial for generating directional tuning in the OFF pathway (Fig. 5). Second, OFF tuning appears to be intact for visible stimulation at eye opening, which presumably also lacks direct activation of OFF bipolar cells.

We speculate that the resolution of these seemingly inconsistent results is in the relative amount of excitation that comes from direct versus crossover inputs for the different stimulation paradigms. Crossover inputs from visible stimulation provide $\sim 60 \%$ of the excitation for OFF SACs while providing $<25 \%$ of the excitation for UV stimulation (Fig. 6D). Therefore, the weaker crossover inputs for UV stimulation activates the OFF cBCs significantly less than visible stimulation, providing less excitatory input for DSGCs.

It is also important to note that, although crossover inputs are intact, they may also provide weaker excitation than in the adult because of an immature synapse between AII amacrine and OFF cBCs. Not only does glycine release from AII amacrine cells undergo a dramatic increase in efficacy after eye opening (which, on its own, could increase disinhibition to OFF SACs), but the exocytosis of glycinergic vesicles is very dependent upon the extent of excitatory input (Balakrishnan et al., 2015). Therefore, without a fully mature ON pathway providing excitation onto the AII amacrine cell, there may be insufficient glycine release in younger retinas to produce a robust disinhibition of OFF $\mathrm{cBCs}$, leading to the reduced direction selectivity observed.

There still remains the question of why visible stimulation evokes significant directional tuning in the OFF pathway, whereas UV stimulation does not. The intensity of the visible stimulation used for recordings near eye opening was in the mesoscopic regime $\left(3 \times 10^{4}\right.$ photons $\left./ \mathrm{s} / \mu^{2}{ }^{2}\right)$ for comparable activation of the rods with both UV and visible light (see Table 1). Therefore, the difference is in the extent of S-cone versus M-cone activation and their downstream bipolar cells. Although chromatic differences in targeting of different bipolar cell types has been explored in the adult mouse (Haverkamp et al., 2005; Breuninger et al., 2011; Wang et al., 2011; Euler et al., 2014), the specificity of wiring during development is unknown. Whether activity plays a role in the establishment of these synapses in the later maturing OFF pathway similar to what has been demonstrated for the ON pathway (Morgan et al., 2011; Dunn et al.,
2013; Johnson and Kerschensteiner, 2014) remains to be determined.

\section{References}

Allen AE, Cameron MA, Brown TM, Vugler AA, Lucas RJ (2010) Visual responses in mice lacking critical components of all known retinal phototransduction cascades. PLoS One 5:e15063. CrossRef Medline

Applebury ML, Antoch MP, Baxter LC, Chun LL, Falk JD, Farhangfar F, Kage K, Krzystolik MG, Lyass LA, Robbins JT (2000) The murine cone photoreceptor: a single cone type expresses both $\mathrm{S}$ and $\mathrm{M}$ opsins with retinal spatial patterning. Neuron 27:513-523. CrossRef Medline

Baden T, Schubert T, Chang L, Wei T, Zaichuk M, Wissinger B, Euler T (2013) A tale of two retinal domains: near-optimal sampling of achromatic contrasts in natural scenes through asymmetric photoreceptor distribution. Neuron 80:1206-1217. CrossRef Medline

Balakrishnan V, Puthussery T, Kim MH, Taylor WR, von Gersdorff H (2015) Synaptic vesicle exocytosis at the dendritic lobules of an inhibitory interneuron in the mammalian retina. Neuron 87:563-575. CrossRef Medline

Borghuis BG, Looger LL, Tomita S, Demb JB (2014) Kainate receptors mediate signaling in both transient and sustained OFF bipolar cell pathways in mouse retina. J Neurosci 34:6128-6139. CrossRef Medline

Breuninger T, Puller C, Haverkamp S, Euler T (2011) Chromatic bipolar cell pathways in the mouse retina. J Neurosci 31:6504-6517. CrossRef Medline

Briggman KL, Helmstaedter M, Denk W (2011) Wiring specificity in the direction-selectivity circuit of the retina. Nature 471:183-188. CrossRef Medline

Calvert PD, Krasnoperova NV, Lyubarsky AL, Isayama T, Nicoló M, Kosaras B, Wong G, Gannon KS, Margolskee RF, Sidman RL, Pugh EN Jr, Makino CL, Lem J (2000) Phototransduction in transgenic mice after targeted deletion of the rod transducin alpha -subunit. Proc Natl Acad Sci U S A 97:13913-13918. CrossRef Medline

Chen H, Liu X, Tian N (2014) Subtype-dependent postnatal development of direction- and orientation-selective retinal ganglion cells in mice. J Neurophysiol 112:2092-2101. CrossRef Medline

Demb JB, Singer JH (2012 Intrinsic properties and functional circuitry of the AII amacrine cell. Vis Neurosci 29:51-60. Medline

DeVries SH, Baylor DA (1995) An alternative pathway for signal flow from rod photoreceptors to ganglion cells in mammalian retina. Proc Natl Acad Sci U S A 92:10658-10662. CrossRef Medline

Ding H, Smith RG, Poleg-Polsky A, Diamond JS, Briggman KL (2016) Species-specific wiring for direction selectivity in the mammalian retina. Nature 535:105-110. CrossRef Medline

Dunn FA, Della Santina L, Parker ED, Wong RO (2013) Sensory experience shapes the development of the visual system's first synapse. Neuron 80 : 1159-1166. CrossRef Medline

Eggers ED, Mazade RE, Klein JS (2013) Inhibition to retinal rod bipolar cells is regulated by light levels. J Neurophysiol 110:153-161. CrossRef Medline

Elstrott J, Anishchenko A, Greschner M, Sher A, Litke AM, Chichilnisky EJ, Feller MB (2008) Direction selectivity in the retina is established independent of visual experience and cholinergic retinal waves. Neuron 58: 499-506. Medline

Euler T, Haverkamp S, Schubert T, Baden T (2014) Retinal bipolar cells: elementary building blocks of vision. Nat Rev Neurosci 15:507-519. CrossRef Medline

Gong S, Zheng C, Doughty ML, Losos K, Didkovsky N, Schambra UB, Nowak NJ, Joyner A, Leblanc G, Hatten ME, Heintz N (2003) A gene expression atlas of the central nervous system based on bacterial artificial chromosomes. Nature 425:917-925.

Govardovskii VI, Calvert PD, Arshavsky VY (2000) Photoreceptor light adaptation. Untangling desensitization and sensitization. J Gen Physiol 116: 791-794.

Grimes WN, Graves LR, Summers MT, Rieke F (2015) A simple retinal mechanism contributes to perceptual interactions between rod- and cone-mediated responses in primates. Elife 4. CrossRef Medline

Hack I, Koulen P, Peichl L, Brandstätter JH (2002) Development of glutamatergic synapses in the rat retina: the postnatal expression of ionotropic glutamate receptor subunits. Vis Neurosci 19:1-13. CrossRef Medline

Haverkamp S, Wässle H, Duebel J, Kuner T, Augustine GJ, Feng G, Euler T 
(2005) The primordial, blue-cone color system of the mouse retina. J Neurosci 25:5438-5445. CrossRef Medline

Hoggarth A, McLaughlin AJ, Ronellenfitch K, Trenholm S, Vasandani R, Sethuramanujam S, Schwab D, Briggman KL, Awatramani GB (2015) Specific wiring of distinct amacrine cells in the directionally selective retinal circuit permits independent coding of direction and size. Neuron 86:276-291. CrossRef Medline

Hoon M, Okawa H, Della Santina L, Wong RO (2014) Functional architecture of the retina: development and disease. Prog Retin Eye Res 42:44-84. CrossRef Medline

Huberman AD, Wei W, Elstrott J, Stafford BK, Feller MB, Barres BA (2009) Genetic identification of an On-Off direction-selective retinal ganglion cell subtype reveals a layer-specific subcortical map of posterior motion. Neuron 62:327-334. CrossRef Medline

Ichinose T, Hellmer CB (2016) Differential signalling and glutamate receptor compositions in the OFF bipolar cell types in the mouse retina. J Physiol 594:883-894. CrossRef Medline

Joesch M, Meister M (2016) A neuronal circuit for colour vision based on rod-cone opponency. Nature 532:236-239. CrossRef Medline

Johnson RE, Kerschensteiner D (2014) Retrograde plasticity and differential competition of bipolar cell dendrites and axons in the developing retina. Curr Biol 24:2301-2306. CrossRef Medline

Ke JB, Wang YV, Borghuis BG, Cembrowski MS, Riecke H, Kath WL, Demb JB, Singer JH (2014) Adaptation to background light enables contrast coding at rod bipolar cell synapses. Neuron 81:388-401. CrossRef Medline

Kim JS, Greene MJ, Zlateski A, Lee K, Richardson M, Turaga SC, Purcaro M, Balkam M, Robinson A, Behabadi BF, Campos M, Denk W, Seung HS; EyeWirers (2014) Space-time wiring specificity supports direction selectivity in the retina. Nature 509:331-336. CrossRef Medline

Kittila CA, Massey SC (1995) Effect of ON pathway blockade on directional selectivity in the rabbit retina. J Neurophysiol 73:703-712. Medline

Lindstrom SH, Ryan DG, Shi J, DeVries SH (2014) Kainate receptor subunit diversity underlying response diversity in retinal off bipolar cells. J Physiol 592:1457-1477. CrossRef Medline

Lipin MY, Taylor WR, Smith RG (2015) Inhibitory input to the directionselective ganglion cell is saturated at low contrast. J Neurophysiol 114: 927-941. CrossRef Medline

Manookin MB, Beaudoin DL, Ernst ZR, Flagel LJ, Demb JB (2008) Disinhibition combines with excitation to extend the operating range of the OFF visual pathway in daylight. J Neurosci 28:4136-4150. CrossRef Medline

Manu M, Baccus SA (2011) Disinhibitory gating of retinal output by transmission from an amacrine cell. Proc Natl Acad Sci U S A 108:1844718452. CrossRef Medline

Mazade RE, Eggers ED (2013) Light adaptation alters the source of inhibition to the mouse retinal OFF pathway. J Neurophysiol 110:2113-2128. CrossRef Medline

Molnar A, Hsueh HA, Roska B, Werblin FS (2009) Crossover inhibition in the retina: circuitry that compensates for nonlinear rectifying synaptic transmission. J Comput Neurosci 27:569-590. CrossRef Medline

Morgan JL, Soto F, Wong RO, Kerschensteiner D (2011) Development of cell type-specific connectivity patterns of converging excitatory axons in the retina. Neuron 71:1014-1021. CrossRef Medline

Morrie RD, Feller MB (2015) An asymmetric increase in inhibitory synapse number underlies the development of a direction selective circuit in the retina. J Neurosci 35:9281-9286. CrossRef Medline

Oesch NW, Kothmann WW, Diamond JS (2011) Illuminating synapses and circuitry in the retina. Curr Opin Neurobiol 21:238-244. CrossRef Medline

Oltedal L, Hartveit E (2010) Transient release kinetics of rod bipolar cells revealed by capacitance measurement of exocytosis from axon terminals in rat retinal slices. J Physiol 588:1469-1487. CrossRef Medline

Park SJ, Kim IJ, Looger LL, Demb JB, Borghuis BG (2014) Excitatory synaptic inputs to mouse on-off direction-selective retinal ganglion cells lack direction tuning. J Neurosci 34:3976-3981. CrossRef Medline

Poleg-Polsky A, Diamond JS (2016) Retinal circuitry balances contrast tuning of excitation and inhibition to enable reliable computation of direction selectivity. J Neurosci 36:5861-5876. CrossRef Medline
Puller C, Ivanova E, Euler T, Haverkamp S, Schubert T (2013) OFF bipolar cells express distinct types of dendritic glutamate receptors in the mouse retina. Neuroscience 243:136-148. CrossRef Medline

Puthussery T, Percival KA, Venkataramani S, Gayet-Primo J, Grünert U, Taylor WR (2014) Kainate receptors mediate synaptic input to transient and sustained OFF visual pathways in primate retina. J Neurosci 34:76117621. CrossRef Medline

Rivlin-Etzion M, Wei W, Feller MB (2012) Visual stimulation reverses the directional preference of direction-selective retinal ganglion cells. Neuron 76:518-525. CrossRef Medline

Rivlin-Etzion M, Zhou K, Wei W, Elstrott J, Nguyen PL, Barres BA, Huberman AD, Feller MB (2011) Transgenic mice reveal unexpected diversity of on-off direction-selective retinal ganglion cell subtypes and brain structures involved in motion processing. J Neurosci 31:8760-8769. CrossRef Medline

Roberts MR, Srinivas M, Forrest D, Morreale de Escobar G, Reh TA (2006) Making the gradient: thyroid hormone regulates cone opsin expression in the developing mouse retina. Proc Natl Acad Sci U S A 103:6218-6223. CrossRef Medline

Röhlich P, van Veen T, Szél A (1994) Two different visual pigments in one retinal cone cell. Neuron 13:1159-1166. CrossRef Medline

Szikra T, Trenholm S, Drinnenberg A, Jüttner J, Raics Z, Farrow K, Biel M, Awatramani G, Clark DA, Sahel JA, da Silveira RA, Roska B (2014) Rods in daylight act as relay cells for cone-driven horizontal cell-mediated surround inhibition. Nat Neurosci 17:1728-1735. CrossRef Medline

Tikidji-Hamburyan A, Reinhard K, Seitter H, Hovhannisyan A, Procyk CA, Allen AE, Schenk M, Lucas RJ, Münch TA (2015) Retinal output changes qualitatively with every change in ambient illuminance. Nat Neurosci 18:66-74. CrossRef Medline

Vlasits AL, Bos R, Morrie RD, Fortuny C, Flannery JG, Feller MB, RivlinEtzion M (2014) Visual stimulation switches the polarity of excitatory input to starburst amacrine cells. Neuron 83:1172-1184. CrossRef Medline

Vlasits AL, Morrie RD, Tran-Van-Minh A, Bleckert A, Gainer CF, DiGregorio DA, Feller MB (2016) A role for synaptic input distribution in a dendritic computation of motion direction in the retina. Neuron 89:13171330. CrossRef Medline

Wang YV, Weick M, Demb JB (2011) Spectral and temporal sensitivity of cone-mediated responses in mouse retinal ganglion cells. J Neurosci 31: 7670-7681. CrossRef Medline

Watanabe D, Inokawa H, Hashimoto K, Suzuki N, Kano M, Shigemoto R, Hirano T, Toyama K, Kaneko S, Yokoi M, Moriyoshi K, Suzuki M, Kobayashi K, Nagatsu T, Kreitman RJ, Pastan I, Nakanishi S (1998) Ablation of cerebellar Golgi cells disrupts synaptic integration involving GABA inhibition and NMDA receptor activation in motor coordination. Cell 95:17-27. CrossRef Medline

Wei W, Elstrott J, Feller MB (2010) Two-photon targeted recording of GFPexpressing neurons for light responses and live-cell imaging in the mouse retina. Nat Protoc 5:1347-1352. CrossRef Medline

Wei W, Hamby AM, Zhou K, Feller MB (2011) Development of asymmetric inhibition underlying direction selectivity in the retina. Nature 469:402406. CrossRef Medline

Werblin FS (2010) Six different roles for crossover inhibition in the retina: correcting the nonlinearities of synaptic transmission. Vis Neurosci 27: 1-8. CrossRef Medline

Werblin FS (2011) The retinal hypercircuit: a repeating synaptic interactive motif underlying visual function. J Physiol 589:3691-3702. CrossRef Medline

Yonehara K, Balint K, Noda M, Nagel G, Bamberg E, Roska B (2011) Spatially asymmetric reorganization of inhibition establishes a motionsensitive circuit. Nature 469:407-410. CrossRef Medline

Yonehara K, Farrow K, Ghanem A, Hillier D, Balint K, Teixeira M, Jüttner J, Noda M, Neve RL, Conzelmann KK, Roska B (2013) The first stage of cardinal direction selectivity is localized to the dendrites of retinal ganglion cells. Neuron 79:1078-1085. CrossRef Medline

Yoshida K, Watanabe D, Ishikane H, Tachibana M, Pastan I, Nakanishi S (2001) A key role of starburst amacrine cells in originating retinal directional selectivity and optokinetic eye movement. Neuron 30:771-780. 